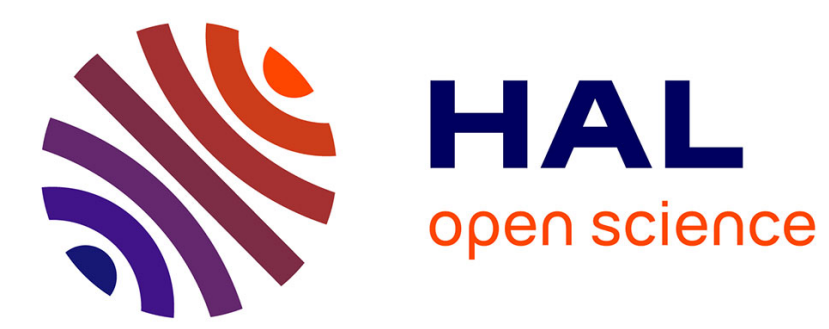

\title{
Vitamin D and multiple sclerosis: An update
}

Charles Pierrot-Deseilligny, Jean-Claude Souberbielle

\section{To cite this version:}

Charles Pierrot-Deseilligny, Jean-Claude Souberbielle. Vitamin D and multiple sclerosis: An update. Multiple Sclerosis and Related Disorders, 2017, 14, pp.35-45. 10.1016/j.msard.2017.03.014 . hal01501453

\section{HAL Id: hal-01501453 \\ https://hal.sorbonne-universite.fr/hal-01501453}

Submitted on 4 Apr 2017

HAL is a multi-disciplinary open access archive for the deposit and dissemination of scientific research documents, whether they are published or not. The documents may come from teaching and research institutions in France or abroad, or from public or private research centers.
L'archive ouverte pluridisciplinaire HAL, est destinée au dépôt et à la diffusion de documents scientifiques de niveau recherche, publiés ou non, émanant des établissements d'enseignement et de recherche français ou étrangers, des laboratoires publics ou privés. 


\title{
Review Article \\ Vitamin D and multiple sclerosis: an update
}

\author{
Charles Pierrot-Deseilligny $^{\mathrm{a} *}$ and Jean-Claude Souberbielle ${ }^{\mathrm{b}}$
}

\begin{abstract}
${ }^{a}$ Département de Neurologie, Hôpital de la Salpêtrière, Assistance Publique Hôpitaux de Paris, Université Pierre et Marie Curie (Paris VI), 47 bd de l'Hôpital, 75013 Paris, France.

${ }^{\mathrm{b}}$ Service d'explorations fonctionnelles, Hôpital Necker-Enfants Malades, Assistance Publique Hôpitaux de Paris, Université René Descartes (Paris V), 149 rue de Sèvres, 75915 Paris, France.

*Corresponding author

E-mail addresses: cp.deseilligny@aphp.fr (C. Pierrot-Deseilligny), jean-claude.souberbielle@aphp.fr (J-C. Souberbielle)
\end{abstract}

\section{Highlights:}

- Genetics has confirmed that hypovitaminosis $D$ is one of the risk factors for MS.

- A modulation of the global risk for MS may exist from conception to the disease onset.

- The main mechanism of action of vitamin D in MS appears to be immunomodulatory.

- Vitamin D could mainly be active in the inflammatory component of MS.

- Systematic moderate vitamin D supplementation of MS patients is recommended.

Abstract. The most recent findings linking exposure to sun and vitamin D insufficiency to multiple sclerosis (MS) are reviewed. Due to insufficient sunshine and changing lifestyles, hypovitaminosis D is widespread in temperate countries. Numerous epidemiological studies have strongly suggested that sunshine and vitamin D insufficiency contributes to MS risk in these countries. Moreover, several large genetic studies in MS patients have recently stated unequivocally that diverse abnormalities involving vitamin D metabolism are related to the risk of the disease. The important implications of such results are discussed here. Then, the interactions of hypovitaminosis D with the other genetic and environmental protective and risk factors, such as the allele HLA DRB1*1501, Epstein-Barr virus infection, obesity, smoking and sexual hormones, are summarized. Vitamin D insufficiency and sufficiency could be a risk and a protective factor, respectively, among many other factors possibly continuously modulating the global MS risk from the mother's pregnancy to the triggering of MS in adulthood. However, many interactions between these different factors occur more particularly between conception and the end of adolescence, which corresponds to the period of maturation of the immune system and thymus and may be related to the dysimmune nature of the disease. The main mechanisms of action of vitamin D in MS appear to be immunomodulatory, involving the various categories of $\mathrm{T}$ and $\mathrm{B}$ lymphocytes in the general immune system, but neuroprotector and neurotrophic mechanisms could also be exerted at the central nervous system level. Furthermore, several controlled immunological studies performed in MS patients have recently confirmed that vitamin D supplementation has multiple beneficial immunomodulatory effects. However, there is still an enduring absence of major conclusive randomized clinical trials testing vitamin D supplementation in MS patients because of the quasi-insurmountable practical difficulties that exist nowadays in conducting and completing over several years such studies involving the use of a vitamin. Nevertheless, it should be noted that similar robust statistical models used in five different association studies have already predicted a favorable vitamin D effect reducing relapses by $50-70 \%$. If there is now little doubt that vitamin D exerts a beneficial action on the inflammatory component of MS, the results are as yet much less clear for the progressive degenerative component. Lastly, until more information becomes available, vitamin D supplementation of MS patients, using a moderate physiological dose essentially correcting their vitamin insufficiency, is recommended.

Key words: environment; genetics; multiple sclerosis; supplementation; vitamin D

Abbreviations: anti-EBNA1, antibodies against EBV antigen nuclear 1; CIS, clinically isolated syndrome; CNS, central nervous system; CYP27B1, enzyme 1a-hydroxylase; EAE, experimental autoimmune encephalopathy; EBV, Epstein-Barr virus; HLA, human leukocyte antigen; MS, multiple sclerosis; RCTs, randomized clinical trials; UVB, ultraviolet B rays; VDR, vitamin D receptor; VDRE, vitamin D responsive element; Tregs, T regulator lymphocytes

Vitamin D and multiple sclerosis: an update, Multiple Sclerosis and Related Disorders, 2017, in press, DOI : http://dx.doi.org/10.1016/j.msard.2017.03.014 


\section{Introduction}

The key role of vitamin D in bone metabolism has been known for a long time, but our knowledge has developed considerably during the past 15 years about the physiological extra-skeletal actions of this vitamin, in particular its immunodulatory effects (Hayes et al., 2015), which have implications in some inflammatory and autoimmune diseases such as multiple sclerosis (MS). In parallel, great advances have also been made in identifying a number of protective factors and risk factors for MS, including exposure to sun and vitamin D insufficiency, which complexly interact with one another (Ascherio and Munger, 2016). The main recent findings linking vitamin D to MS are reviewed in this update.

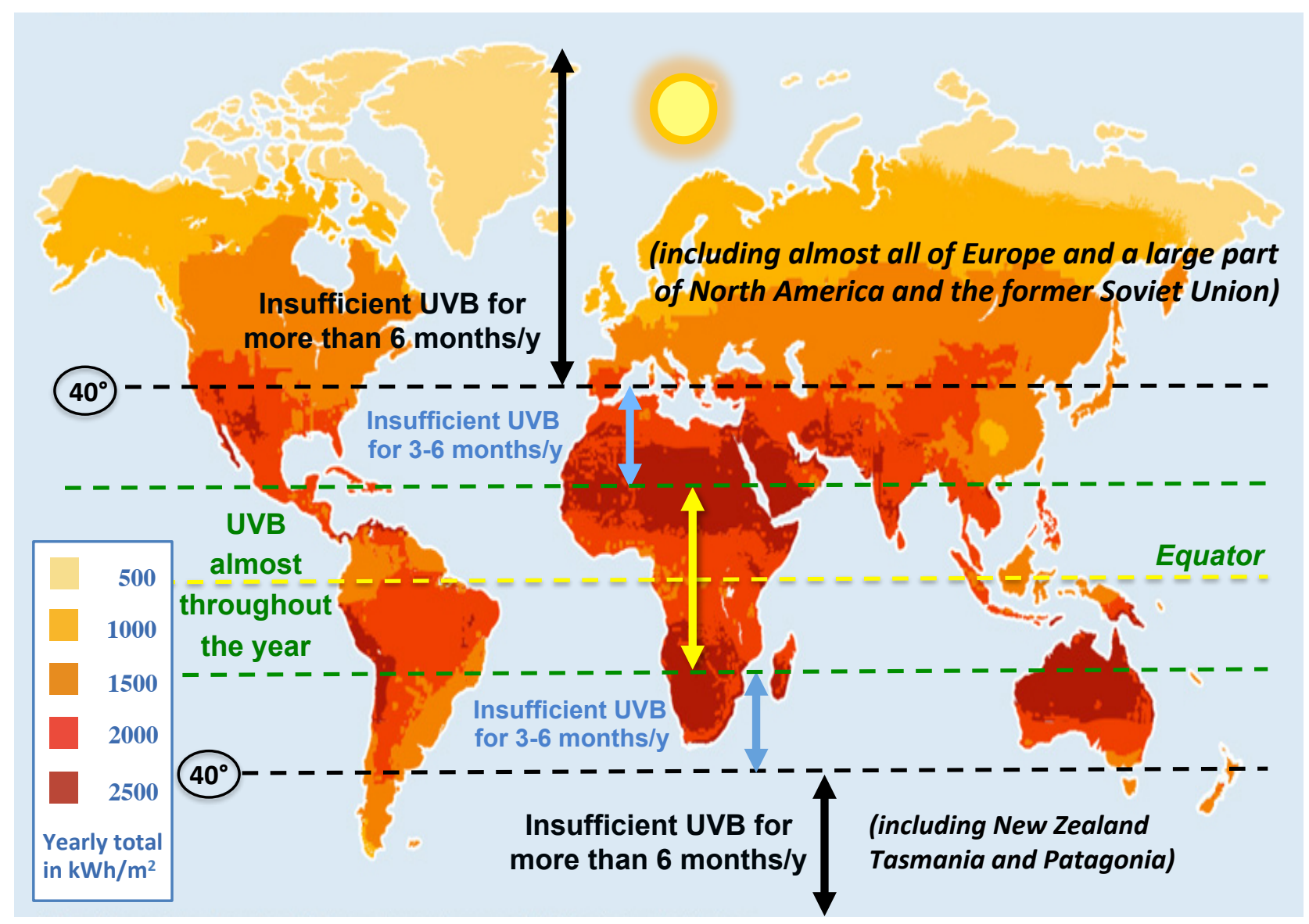

Figure 1. Unequal solar ultraviolet radiation in the world. UVB reach the ground and skin only when the sun is sufficiently high in the sky for UVB to penetrate all the layers of the atmosphere. This physical mechanism can only exist in the middle of the day and, beyond the 40th parallel in mid and high latitude regions, only for a few months of the year, essentially between the middle of spring and the end of summer. Thus, a vast portion of the northern hemisphere - comprising almost all of Europe and a large part of North America and of the former Soviet Union - as well as a few countries in the southern hemisphere - are involved. In all these countries, exposure to sun includes UVB only during these relatively reduced time slots in the day and year. These regions correspond to those where the highest multiple sclerosis prevalence is observed. By contrast, subtropical and tropical regions, where $80 \%$ of the world's population lives, have enough sunshine to provide the major source of natural vitamin $D$ almost throughout the year. $40^{\circ}$, 40th parallel; UVB, ultraviolet B rays; $\mathrm{kWh} / \mathrm{m}^{2}$ kilowatt/hour per square meter. Adapted from Meteonorm values. 


\section{General and physiological considerations on sunshine and vitamin $D$}

Vitamin D is principally produced by the action of ultraviolet B rays (UVB) in the skin, providing $80-90 \%$ of human requirements (Holick, 2011; Wacker and Holick, 2013), but this main natural solar source of vitamin is unequally distributed in the world (O'Neil et al., 2016), as shown in Figure 1. The metabolism of vitamin D is nowadays relatively well known and is summarized in Figure 2 (Norman and Bouillon, 2010; Pike and Meyer, 2012). 25-OH-D is the vitamin D metabolite usually measured in the blood since it is representative of the vitamin D store in the organism (Souberbielle et al., 2010). The optimal levels for serum 25-OH-D concentration vary according to the target population (Hoel et al., 2016; Holick et al., 2011; Ross et al., 2011). For immune health and more generally for patients, the target 25-OH-D range usually accepted nowadays (30$60 \mathrm{ng} / \mathrm{mL}$ or $75-150 \mathrm{nmol} / \mathrm{L}$ ) has been derived from multiple metabolic and bone clinical data (Binkley and Krueger, 2008; Holick et al., 2011; Pierrot-Deseilligny and Souberbielle, 2013): these findings are very different in nature but, quite remarkably, they all indicate the critical feature of the lower limit (30 ng/mL), below which a pathological significance is reached. This is why those norms are nowadays often recommended (Hoel et al., 2016), even though there is not yet a total consensus (Holick et al., 2011; Pludowski et al., 2013; Ross et al., 2011; Souberbielle et al., 2010).

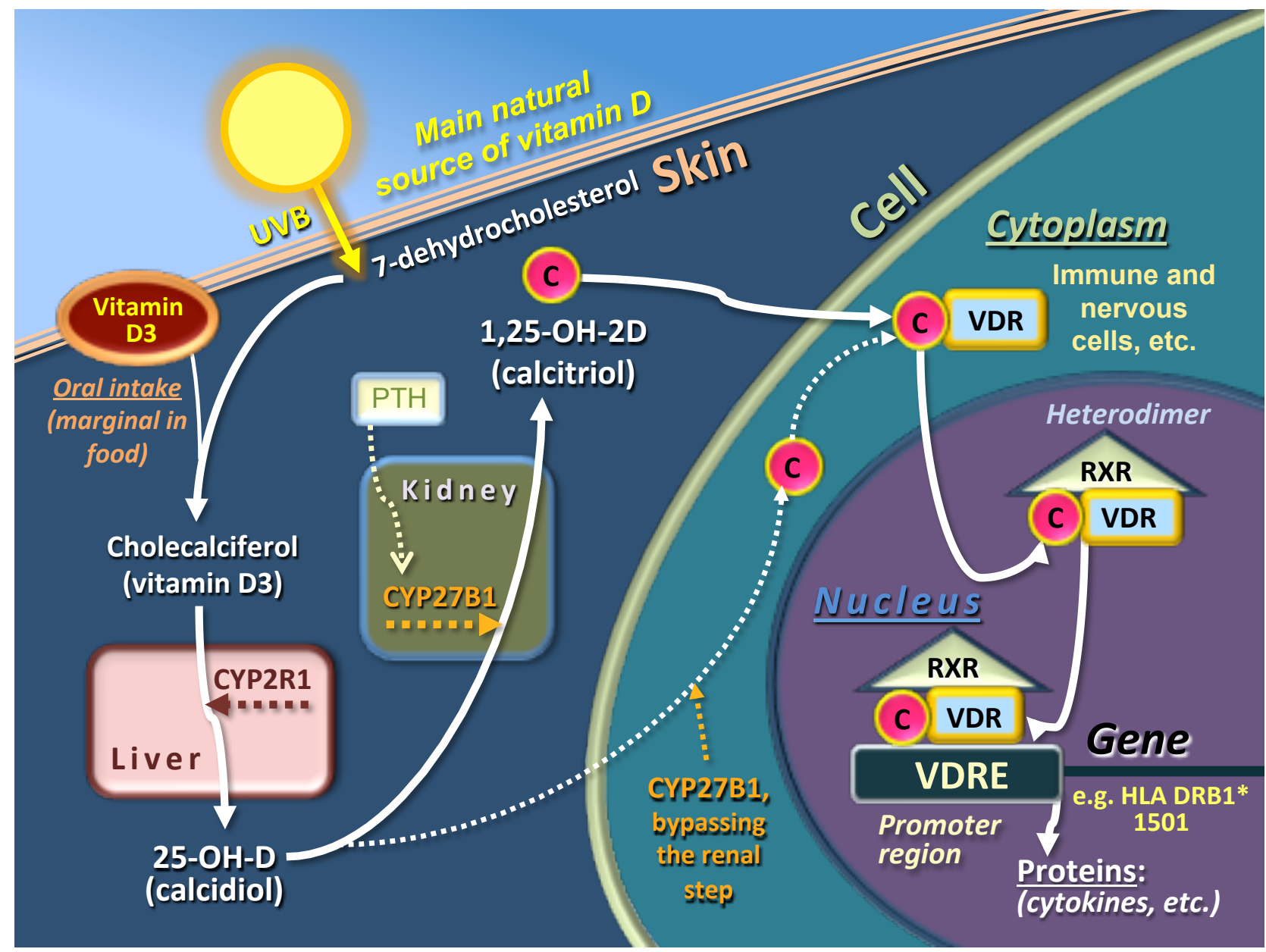

Figure 2. Schematic representation of vitamin $D$ metabolism. Vitamin $D_{3}$ is mainly synthesized at the skin level thanks to UVB and, after a double hydroxylation in the liver and the kidney, is transformed into calcitriol, i.e. the active metabolite. Calcitriol can also be directly synthesized in the cell cytoplasm from the circulating 25-OH-D and links at this level to a specific receptor (VDR), which is present in numerous cells of the organism, including immune and nervous cells. Then, this complex penetrates into the nucleus, forms a heterodimer with the receptor RXR and this heterodimer finally binds to VDRE, which constitutes a specific sequence of DNA within the promoter region of the target genes. The whole regulates (by activation or suppression) gene transcription and expression and, ultimately, protein synthesis in approximately 5-10\% of the genome. Thus, for immune cells, which are particularly involved in MS pathogenesis, the synthesis of the diverse favorable and unfavorable cytokines related to inflammatory mechanisms could be either increased or decreased depending on the genes and the vitamin $D$ status at the time (see below in the text). Note that the allele HLA DRB1*1501, which is particularly deleterious in terms of MS risk and taken here as example, possesses a VDRE area. C, calcitriol; CYP27B, enzyme 1 $\alpha$-hydroxylase; CYP2R, enzyme 25hydroxylase; HLA, human leukocyte antigen; PTH, parathyroid hormone; RXR, retinoid X receptor; UVB, ultraviolet B rays; VDR, vitamin D receptor; VDRE, vitamin D responsive element. 
To reach a 25-OH-D serum level above $30 \mathrm{ng} / \mathrm{mL}$ and then permanently maintain it within the physiological zone $(30-60 \mathrm{ng} / \mathrm{mL})$, one must receive a daily vitamin $\mathrm{D}$ dose of between 2000 and 4000 IU (3000 IU on average) (Bischoff-Ferrari et al., 2012; Hall et al., 2010; Wacker and Holick, 2013), which is naturally observed only in outdoor workers during the summer (Azizi et al., 2012; Bager-Lux and Heaney, 2002) or in tropical countries (Luxwolda et al., 2012). Indeed, food, even in a wellbalanced diet, provides only about $100 \mathrm{IU} / \mathrm{d}$ and, if fortified, not more than 300-400 IU/d, which is in any case insufficient (Holick, 2012). Moreover, the organism does not durably store vitamin $D$, which progressively disappears within 6-8 weeks after a single solar or oral intake. The so-called 'toxic' area, potentially generating hypercalcemia, seems to be located largely above $150 \mathrm{ng} / \mathrm{mL}$, corresponding to a daily intake far higher than 10,000 IU/d (Hathcock et al., 2007).

These multiple considerations - physical, geographical, societal and physiological - explain why vitamin D insufficiency is widespread nowadays in the general population of temperate countries, and how this problem has progressively worsened during the last hundred years as a corollary of the development of the modern lifestyle which has progressively taken these populations away from direct exposure to sunshine (Pierrot-Deseilligny and Souberbielle, 2010).

\section{Role of vitamin $D$ in the risk for MS}

\subsection{Epidemiology of latitude and solar radiation effects on the MS risk}

It has long been known that latitude influences MS risk, the prevalence of the disease being minimal at the equator and increasing with North or South latitude (Simpson et al., 2011). Furthermore, MS prevalence may change after migrations that occurred during the second decade of life, with a beneficial effect for people who migrated from a high-latitude region (with a high MS prevalence) to a sunnier, lower-latitude region, with a low MS prevalence (Handel et al., 2010; McLeod et al., 2011). It has also been reported that the MS prevalence of a region is inversely correlated to the level of solar radiation of this region, always with a high level of significance, on a world scale (Sloka et al., 2011), in the USA (Beretich and Beretich, 2009), in France (Pierrot-Deseilligny and Souberbielle, 2010) and the United Kingdom (Ramagopalan et al. 2011), thus explaining the well-known link between MS risk and latitude. It is also known that the time spent outdoors during childhood and adolescence has an impact on MS risk: people who practiced many outdoor activities during their youth, and thus received more UVB, have a significantly lower risk later for MS (Bjørnevik et al., 2014; Laursen et al., 2016a; Van der Mei et al., 2003). In spite of methodological debates (Fides et al., 2014), the month of birth does also appear to influence the MS risk: people born at the end of autumn, i.e. whose mothers could have had a relatively good exposure to sun in the major part of pregnancy, have a significantly reduced MS risk, whereas those born at the end of spring, whose mothers likely had much less exposure to sun in the major part of pregnancy, have an increased MS risk, these findings existing in both hemispheres, in which seasons are reversed (Balbuena et al., 2016; Dobson et al., 2013; Rodriguez Cruz et al., 2016).

\subsection{Specific UVB effects on the MS risk}

From a general point of view, vitamin D is likely a major intermediary link between exposure to sun and the MS risk since UVB physiologically produce directly this vitamin in the organism. However, it may also be that UVB play a beneficial role in immunity through a specific immunomodulatory effect that could be independent of the vitamin D synthesis (Breuer et al., 2014; DelLuca and Plum, 2017; Hart and Gorman, 2013) (see Figure 3). Although the respective immunological vitamin D and UVB effects from the skin and its different outlet pathways are not easy to differentiate and delineate in humans, the possibly specific UVB action may be exerted in parallel to the immunomodulatory effect of vitamin D (Lucas et al. 2015), which is currently far more widely documented (see below). In any case, these two mechanisms do not exclude each other and their possibly different specific actions have even been differentiated in a few epidemiological studies (Bäärnhielm et al., 2012; Lucas et al., 2011). 


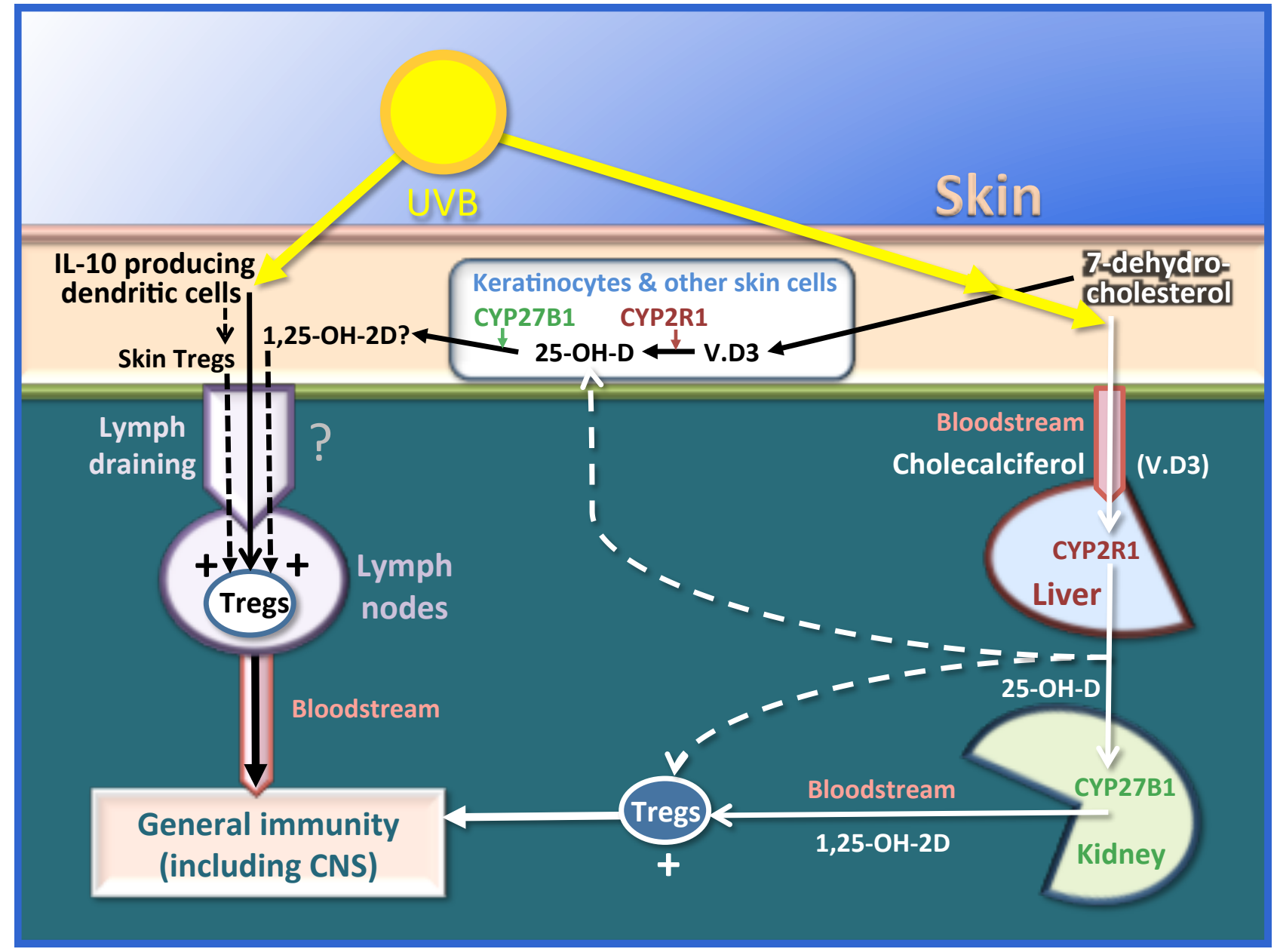

Figure 3. The two main pathways through which UVB may influence immunity. The first, classical pathway (right) starts in the skin under the influence of UVB with the transformation of 7dehydrocholesterol into cholecalciferol (vitamin $D_{3}$ ), which then passes through the bloodstream into the liver and the kidneys and results in calcitriol (the active metabolite) stimulating Tregs, having a beneficial immunomodulatory effect on the general immunity (see below in the text). The second pathway (left), as yet much less well known, could be partly independent of the vitamin D synthesis: the UBV could also stimulate skin-derived tolerogenic dendritic cells, producing IL-10 (a favorable cytokine), resulting in stimulation of local Tregs and also, after moving through lymph draining, of Tregs located in the lymph nodes. Tregs finally join through the bloodstream the general immune system, in which they could also have a beneficial action. However, it should be noted that calcitriol may also be locally produced within the skin from 7-dehydrochlesterol or the circulating 25-OH-D in the keratinocytes and other skin cells, which have a complete enzymatic equipment to do this (Lehmann, 2009). Furthermore, calcitriol could be used in the skin (McCully et al., 2015; Schuessler et al. 2001) and captured, through lymph draining, by the lymph nodes (Gorman et al., 2007), where it might also stimulate the local Tregs. Thus, this possible further pathway involving vitamin $D$ within the skin itself complicates the study of a specific, independent role of UVB in immunity. 1,25-OH-2D, calcitriol; 25-OH-D, calcidiol; CNS, central nervous system; CYP27B1, enzyme 1 $\alpha$-hydroxylase; CYP2R1, enzyme 25-hydroxylase; Tregs, T regulator lymphocytes; UVB, ultraviolet $B$ rays; $V .3$, vitamin $D_{3}$.

\subsection{Epidemiology of vitamin D effects on the MS risk}

In fact, the direct epidemiological link between vitamin D and the MS risk has been suggested in studies in which the consumption of vitamin D supplements during youth (Munger et al., 2004), cod liver oil during adolescence (Cortese et al., 2015) or fatty fish (rich in vitamin D) (Bäärnhielm et al., 2014) appeared to provide significant protective effects for the MS risk later in life. In another study, young American soldiers who had a spontaneous 25-OH-D serum level above $40 \mathrm{ng} / \mathrm{mL}$ had a $62 \%$ lower MS risk than those with less than $25 \mathrm{ng} / \mathrm{mL}$ (Munger et al., 2006). More recently, analogous findings were observed in Swedish pregnant women in whom those with a 25-OH-D serum level above $30 \mathrm{ng} / \mathrm{mL} \mathrm{had}$ a $61 \%$ lower MS risk than those with less than $30 \mathrm{ng} / \mathrm{mL}$ (Salzer et al., 2012). Vitamin D status during 
pregnancy also played a significant role in the MS risk of offspring in two other studies, in the USA (Mirzaei et al., 2011) and in Finland (Munger et al., 2016). Lastly, in a recent Danish study, the 25-OH-D serum level of newborns appeared to influence their MS risk 15-30 years later, with the observation that for each increase of $20 \mathrm{ng} / \mathrm{mL}$ in the serum level the MS risk was decreased by $60 \%$ (Nielsen et al., 2017). Accordingly, the results of these multiple studies strongly suggest that an insufficiency in exposure to sun and/or in vitamin D during the first part of life constitutes a major risk for MS, with as a corollary a consistent quantified reduction of about $60 \%$ of this risk resulting from a normal vitamin D serum level.

\subsection{Contribution of genetic abnormalities of the vitamin D metabolism to the MS risk}

Lastly, vitamin D insufficiency contributes to MS susceptibility as both an environmental and a genetic risk factor. Genetic studies in MS patients are numerous but we will focus here only on the major recent advances that have linked in a non-ambiguous way diverse specific genetic errors in the vitamin D metabolism to MS risk. Abnormalities of the gene of enzyme $1 \alpha$-hydroxylase (CYP27B1) (Sawcer et al., 2011), which specifically controls calcitriol synthesis, significantly influenced the MS risk in studies testing the variants rs703842 (Karaky et al., 2016; Simon et al., 2011; Sundqvist et al., 2010) or rs10877013 (Zhuang et al., 2015). Genetic abnormalities of the CYP24A1 gene, which encodes the enzyme responsible for initiating calcitriol degradation, also influenced MS risk (Ramasamy et al., 2014). Moreover, two vast studies recently aimed to link genetically low 25-OH-D serum levels to the MS risk: the first study, in Canada (Mokry et al., 2015), and the second one, in both the USA and Sweden (Rhead et al., 2016), comprising further methodological criteria, involved thousands of MS patients and control subjects, who were tested using mendelian randomization techniques from several single nucleotide polymorphisms corresponding to different stages of vitamin D metabolism. In the results, very strong links existed between these vitamin D abnormalities and the risk for MS. Accordingly, such studies, in which there was methodologically very little room for reverse causality and confounding factors, state that a genetically induced hypovitaminosis D is a risk factor for MS. This finding has several important implications. First, even if such a relatively rare type of genetic hypovitaminosis D represents a very minor part of currently known forms of MS heritability, dominated by dysimmune abnormalities, it nevertheless provides evidence that hypovitaminosis D per se is a risk factor. Second, it may be inferred from such evidence that the most widespread vitamin D insufficiency, which is not genetically induced but results from unfavorable environmental conditions, is also an MS risk factor, as strongly suggested by the epidemiological studies reviewed above in which this environmental part of the risk seemed even to be a major component. Third, since these genetic studies specifically involve vitamin D metabolism, they also confirm that UVB do not play an exclusive beneficial role in immunity (see above).

\section{Other risk factors for MS and interactions with vitamin D}

\subsection{Role of the human leukocyte antigen system}

For MS there are in fact many other risk factors and protective factors, both genetic and environmental, which could cumulate or compensate one another. Among the other genetic risk factors for MS, the allele DRB1*1501 in the human leukocyte antigen (HLA) system accounts for $11 \%$ of heritability of the disease, whereas other alleles such as HLA-A*0201 could be protective (Sawcer et al., 2011). There is a vitamin D responsive element (VDRE) zone in the promoter region of HLA DRB1*1501 gene which strongly suggests an involvement in mechanisms linked to vitamin $\mathrm{D}$, even if these mechanisms are as yet little known (Ramagopalan et al., 2009). Furthermore, in a recent pediatric study, the allele HLA DRB1*1501 was significantly associated with the 25-OH-D serum level and with the relapse rate (Graves et al., 2016), whereas in another study this allele was related to low exposure to sun and to obesity (Laursen et al., 2015). Lastly HLA DRB1*1501 is over-represented in Caucasian populations and in women and it has been suggested that certain HLA alleles could have evolved during previous generations thanks to epigenetic mechanisms influenced by favorable or unfavorable environmental conditions, in which the vitamin D status could figure (Handunnetthi et al., 2010; Koch et al., 2012) (Figure 4). 


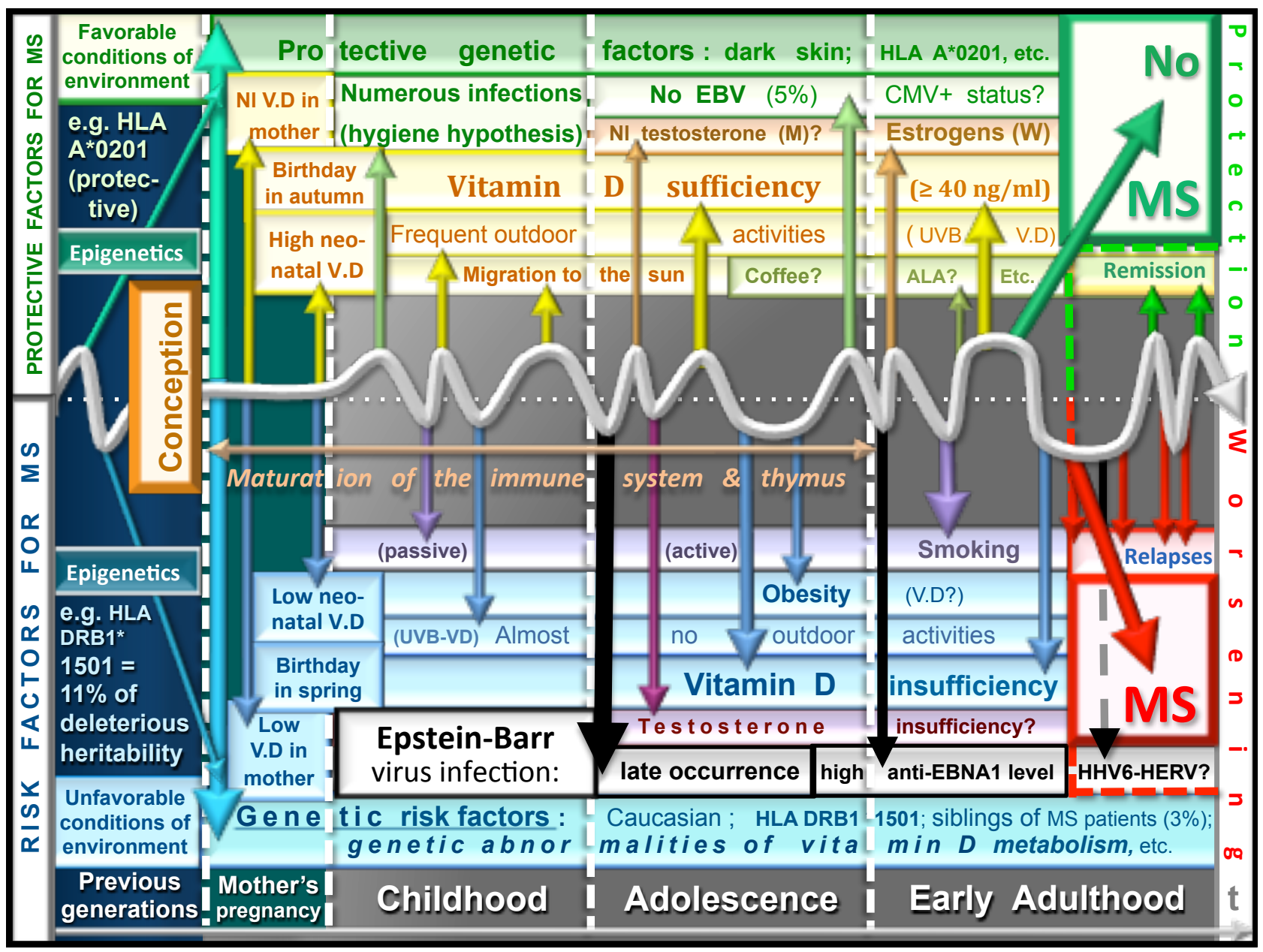

Figure 4. Schematic continuous modulation of protective and risk factors in MS. For more details see text. A schematic curve of the global MS risk, fluctuating with time, is shown in the middle. Hypothetical risk factors for MS (bottom) and protective factors for the disease (top) are both genetic and environmental. The numerous interactions between these different factors may occur (from right to left) in adulthood, in adolescence, in childhood, during the mother's pregnancy and even during previous generations, through epigenetic mechanisms that could shape protective or deleterious alleles in the HLA system depending on favorable or unfavorable environmental conditions. The evolution of the MS risk (left to right) starts at conception, where protective and deleterious genetic factors are transmitted, in particular HLA DRB1*1501 and genes involved in abnormalities of vitamin D metabolism (bottom). Then, a birthday in spring, a high vitamin $D$ serum level during pregnancy, in the newborn or later during the first part of life, but also outside activities during youth (with UVB and/or vitamin D) and migration to a sunny country in adolescence would all be protective elements, whereas the reverse conditions could increase the MS risk. Infection with EBV, responsible for infectious mononucleosis, appears to be a major and possibly founding risk factor for MS, in particular if primo-infection occurs late, after childhood, and/or if it leaves a high level of anti-EBNA1, whereas a negative serologic status to EBV could be protective (5\% of population). The viruses HHV6 and HERVs could also have deleterious effects in terms of MS risk, maybe more particularly during the disease course. By contrast, numerous common infections or parasitic infestations during childhood could be protective, according to the hygiene hypothesis, as would also be positive serology for CMV. Sexual hormones, i.e. testosterone in men and estrogens and progesterone in women, could be protective. Obesity, in particular in adolescence, and cigarette smoking are other risk factors for MS, whereas coffee (at high dose), ALA and other substances could be protective. All these protective and risk factors interact between conception and the triggering of MS, usually occurring in young adulthood, leading to the concept of a continuous modulation of the global MS risk throughout the first part of life. However, many of these interactions intervene between pregnancy and the end of adolescence, in a period corresponding to that of the maturation of the immune system and thymus, which could be related to the dysimmune nature of the disease. Certain combinations of deleterious risk factors could finally trigger the disease, whereas diverse protective effects could prevent it durably. If the disease starts (right), some risk factors could continue to have deleterious effects by worsening its course and favoring relapses, whereas certain protective factors could contribute to remissions. ALA, $\alpha$-linoleic acid; anti-EBNA1, antibodies against EBV antigen nuclear 1; CMV, cytomegalovirus; EBV, Epstein-Barr virus; HERV, human endogenous retrovirus; HHV6, human herpes virus of type 6; HLA, human leukocyte antigen; $M$, men; $M S$, multiple sclerosis; Nl, normal; UVB, ultraviolet B rays; V.D, vitamin D; $W$, women. 


\subsection{Role of viruses and infections}

Among the other environmental risk factors, Epstein-Barr virus (EBV) infection might play a major role (Ascherio and Munger, 2016; Olsson et al., 2017; Salzer et al., 2013; Waubant et al., 2016) (see more details in Figure 4). In MS patients, genetic arguments for interactions between EBV infection and vitamin D have been reported (Ricigliano et al., 2015), with, furthermore, associations existing between HLA DRB1*1501, the 25-OH-D serum level and the serum level of antibodies against EBV antigen nuclear 1 (anti-EBNA1) (Wergeland et al., 2016), or between these last two factors (Salzer et al., 2013). Moreover, vitamin D supplementation appears to decrease the anti-EBNA1 serum level (Røsjø et al., 2017), which might be a beneficial effect. Infections with human herpes virus of type 6 or human endogenous retrovirus could also be MS risk factors and/or factors worsening the disease (Tao et al., 2017). By contrast, the accumulation of numerous common infections and/or infestations with parasites during childhood appears to be protective from the risk of autoimmune diseases occurring later, including MS (Correale and Gaetan, 2015; Gustavsen et al., 2014): this constitutes the 'hygiene' hypothesis, in which a particular development of the protective Tregs could be favorable. Furthermore, links between the mechanisms involved in the hygiene hypothesis and vitamin D may exist, through the vitamin D receptor (VDR) and gut microbiome (Clark and Mach, 2016), the importance of which is beginning to be discovered for the pathogenesis of autoimmune diseases, including MS (Budhram et al., 2016; Mielcraz and Kasper, 2015; Tremlett et al., 2016). Serologic positivity to cytomegalovirus could also be protective (Makhani et al., 2016; Sundqvist et al., 2014; Waubant et al., 2011) due to complex immunological competition with EBV (Chidrawar et al., 2009), in which the 25-OH-D serum levels may also be associated (Mowry et al., 2011).

\subsection{Role of other risk and protective factors}

Obesity has recently been identified as another risk factor for MS, in particular if it exists in childhood or adolescence (Gianfrancesco et al., 2017; Mokry et al., 2016; Munger et al., 2013; Wesnes et al., 2015). Although obesity and vitamin D are partly linked since this vitamin is liposoluble and sequestered in fatty tissues and consequently less available in the blood (Earthman et al., 2012), these two factors could also be partly independent in the MS risk (Gianfrancesco et al., 2017). Sexual hormones, i.e. testosterone in men (Bove et al., 2014) and estrogens and progesterone in women (Patas et al., 2013), could also be protective, with possible links between vitamin D, estrogens and progesterone (see below). Lastly, there are other environmental risk factors for MS, such as cigarette smoking (Ascherio and Munger, 2016; Olsson et al., 2017), even when intoxication is passive in children, whereas the $\alpha$ linolenic acid (Bjørnevik et al., 2017), nicotine (if not smoked), coffee (at high doses), alcohol (at moderate doses) (Olsson et al., 2017) could rather be protective. All these MS risk and protective factors, the list of which is likely not yet exhaustive, appear to be more or less independent of each other and could cumulate or compensate (Ascherio et al., 2012; Ramien et al., 2014).

\subsection{General interactions between protective and risk factors in $M S$}

Thus, vitamin D insufficiency is only one of many risk factors for MS. It is generally accepted that MS results from the association of several genetic and environmental risk factors and it may be assumed that multiple different deleterious combinations between these diverse potential risk factors could lead to its triggering. Likewise, vitamin D sufficiency appears to be one of many protective factors, including diverse genetic, infectious and pharmacological protective factors. Lastly, as emphasized above, all these MS risk and protective factors could interact at different times between conception and MS triggering, which generally occurs during adulthood. This leads to the relatively recent concept of a continuous modulation of the global MS risk taking place throughout the first part of life (Figure 4). However, it should be noted that determining events appear to happen more particularly between the mother's pregnancy and the end of adolescence. This period could correspond to that of the maturation of the immune system and thymus (Tamblyn et al., 2015; Tulic et al., 2012; Vijayendra Chari et al., 2015), during which favorable or unfavorable immunological transformations could be durably constituted, which is likely related to the dysimmune nature of the disease and is reviewed in the next section. 


\section{Mechanisms of action of vitamin D in MS}

\subsection{Immunological mechanisms}

There are potentially multiple mechanisms by which vitamin D influences MS, before or after the disease is triggered. The general immunological effects of this vitamin are currently the best known and are likely involved at the inflammatory period of the disease, but other, central neurological mechanisms could also exert an effect in parallel. MS is a general dysimmune disease, which exclusively involves the central nervous system (CNS). Numerous dysimmune mechanisms have been discussed in MS (Yadav et al., 2015) and it should be noted that a majority of the genes involved in the disease are related to such mechanisms (Sawcer et al., 2011). The general immunomodulatory role of vitamin D has been abundantly documented in recent years, involving the different categories of $\mathrm{T}$ and $\mathrm{B}$ lymphocytes and several cytokines (Allen et al., 2012; Cantorna et al., 2015; Danner et al., 2016; Fawaz et al., 2016; Rolf et al., 2014; Sommer and Fabri, 2015; Von Essen et al., 2010). It is likely through these diverse immunomodulatory mechanisms that vitamin D intervenes in MS, as recently confirmed in numerous immunological studies performed in MS patients (Correale et al., 2009; Grau-Lopez et al., 2012; Lysandropoulos et al., 2011; Smolders et al., 2009; Smolders et al., 2010) that cannot be detailed here but in some of which vitamin D supplementation resulted in multiple beneficial immunological effects: in particular, with stimulation of Tregs (Murris et al., 2016c) and of the favorable IL-10 cytokine (Ashtari et al., 2015; Mosayebi et al., 2011), diminution of the pro-inflammatory Th17 lymphocytes (da Costa et al., 2016) and the deleterious cytokine IL-17 (Sotirchos et al., 2016), and attenuation of B-cell immunoreactivity (Haas et al., 2016). Although these studies usually comprised small numbers of patients, with a follow-up of less than 6 months and without analysis of clinical parameters, they were nevertheless usually controlled and thus have allowed it to be stated unequivocally that vitamin $\mathrm{D}$ has positive immunological effects in MS.

The same immunomodulatory mechanisms also appear to be involved in experimental autoimmune encephalopathy (EAE) (Cantorna et al., 2015), which is the best experimental model of MS. The numerous studies on vitamin D in EAE published during the past 25 years cannot be detailed here but they have generally shown a preventive and curative action of this vitamin, more particularly in female mice (Cantorna et al., 2015). Moreover, it was experimentally reported that vitamin D and estrogens act synergistically in stimulating different favorable immunomodulatory effects (Spanier et al., 2015). An analogous synergy between progesterone and vitamin D could also stimulate immunomodulation (Thangamani et al., 2015). In humans, it is known that estrogens (Nadkami and McArthur, 2013) and progesterone (Tan et al., 2015) have specific immunomodulatory actions and that pregnancy has rather a protective effect in terms of risk for MS development, most likely due to the physiologically elevated hormonal levels reinforcing general immunomodulation (Nair et al., 2017). In the context of the widespread hypovitaminosis D in countries with little sunshine, a phenomenon that has increased over the past tens of years due to changing lifestyles (Looker et al., 2008), a decrease in immunomodulatory synergies between vitamin $\mathrm{D}$ and female hormones, without a similar potentiation existing between vitamin D and testosterone (Bove et al., 2014; Zhao et al., 2017), could have had a more deleterious impact in women than in men and thus might have contributed to the well-known and increasing female predominance in MS (Spanier et al., 2015). Furthermore, such immunomodulatory synergies could account for a more beneficial effect of vitamin D supplementation observed in women (Kragt et al., 2009).

\subsection{Other possible mechanisms}

Vitamin D, among its diverse extra-skeletal effects, likely has other non-immunomodulatory actions. In particular, this vitamin enters the different types of cells in the CNS - neurons, astrocytes, microglia and oligodendrocytes, which all have VDR - and it could exert at the central neurological level other modes of action, e.g. neuroprotector, neurotrophic, remyelinating, etc. (Smolders et al., 2011). Some experimental results have already been reported in this field (de la Fuente et al., 2015; Shirazi et al., 2015), and a link between axonal degeneration and vitamin D seems to exist in MS patients (Sandberg et al., 2016). However, these other possible central mechanisms remain largely to be explored in human physiology and pathology, i.e. in MS as in other central neurological degenerative diseases. 


\section{Clinical data on vitamin D in MS}

\subsection{Practical difficulties of clinical studies using vitamin D supplementation in MS patients}

Although there is currently very little doubt that vitamin D insufficiency constitutes one of the risk factors for MS before the triggering of the disease, important questions and doubts remain regarding its action once the disease has started. Many studies using vitamin D supplementation have been performed but they were insufficiently powered, most often without a long-lasting follow-up and/or with diverse methodological bias, to be able to produce really conclusive results. A few other, longer, phase 2 or 3 randomized clinical trials (RCTs) are still ongoing but they may also prove to be under-powered due to their already known baseline characteristics and because of the diverse, quasi insurmountable practical difficulties that exist nowadays with conducting and/or completing studies of this type using vitamin D. Indeed, since patients being enrolled in such RCTs testing vitamin D supplementation will necessarily be aware before they sign their initial consent form that they have an insufficiency of a 'vitamin', they often prefer not to participate in the study and, if they do participate, they quit it more or less rapidly or even change their own behavior in regard to vitamin D intake - going out in the sun more frequently and/or using more fortified food and diverse vitamin D supplements than previously - ultimately downsizing the studies or introducing major methodological bias. Only the already published and most reliable clinical results are discussed here.

\subsection{Vitamin D serum levels in MS patients}

Low 25-OH-D serum levels (around $20 \mathrm{ng} / \mathrm{mL}$ ) are usually observed in MS patients as early as the beginning of the disease, i.e. at the stage of the clinically isolated syndrome (CIS) or of the first relapses (Ascherio et al., 2014; Behrens et al., 2016; Kuhle et al., 2015; Martinelli et al., 2014; Pierrot-Deseilligny and Souberbielle, 2010). However, spontaneously normal serum levels (above $30 \mathrm{ng} / \mathrm{mL}$ ) may also be observed in rare MS patients since the disease is multifactorial. The vitamin D insufficiency in MS patients, compared to matched control subjects, could be partly explained by abnormalities in the vitamin metabolism existing in patients (Bhargava et al., 2016). Later in the disease, vitamin D serum levels have a clear tendency to decrease even more, but two associated factors may then favor such a decrease (Pierrot-Deseilligny and Souberbielle, 2013): first, the Uthoff phenomenon, where patients tend to avoid direct sunlight because heat aggravates their symptoms, then disability, with fewer outdoor activities and, consequently, less exposure to UVB. If these two factors can indeed contribute to a reverse causality, in which the disease itself widens the vitamin D deficit, it should not be forgotten that a marked vitamin D insufficiency often already exists as early as the beginning of the disease in young and non-disabled patients in whom such factors cannot yet have played any significant role.

\begin{tabular}{|c|c|c|c|c|c|c|c|c|}
\hline Reference & $\begin{array}{l}\text { Cohort } \\
\text { location }\end{array}$ & MS form & $\begin{array}{l}\text { Number of } \\
\text { patients }\end{array}$ & $\begin{array}{l}\text { Age } \\
\text { (years) }\end{array}$ & $\begin{array}{l}\text { Follow-up } \\
\text { (mean, } \\
\text { years) }\end{array}$ & $\begin{array}{l}\text { Associated } \\
\text { treatment }\end{array}$ & $\begin{array}{l}\text { Associated } \\
\text { vitamin D }\end{array}$ & $\begin{array}{l}\text { Decrease in relapses } \\
\text { for each increase of } \\
20 \mathrm{ng} / \mathrm{mL} \text { in } 25-\mathrm{OH}-\mathrm{D}\end{array}$ \\
\hline $\begin{array}{l}\text { Mowry et al., } \\
2010\end{array}$ & USA & RR-CIS & $\mathrm{n}=110$ & $15 \pm 3$ & 1.7 & No & No & $-68 \%$ \\
\hline $\begin{array}{c}\text { Simpson et al., } \\
2010\end{array}$ & Australia & $\mathrm{RR}$ & $n=145$ & $44 \pm 10$ & 3 & IMT & No & $-50 \%$ \\
\hline $\begin{array}{l}\text { ierrot-Deseilligny } \\
\text { et al., } 2012\end{array}$ & Paris, France & $\mathrm{RR}$ & $n=156$ & $39 \pm 10$ & 2.5 & IMT & Yes & $-68 \%$ \\
\hline $\begin{array}{l}\text { Ascherio et al., } \\
2014\end{array}$ & Multicentric & $\mathrm{CIS}$ & $n=336$ & $35 \pm 9$ & 2 & IMT & No & $-57 \%$ \\
\hline $\begin{array}{l}\text { Laursen et al., } \\
\text { 2016b }\end{array}$ & Denmark & RR & $n=134$ & $41 \pm 9$ & 1 & Natalizumab & Yes & $-70 \%$ \\
\hline
\end{tabular}

Table 1. Association studies between relapses and 25-OH-D serum levels in MS patients. These five studies were comparable in terms of their methodologies, the statistic models used (linear regression, with multivariate analyses), cohort size and the duration of follow-ups. Note that the first study was pediatric and that the third and fifth studies were association-intervention studies with vitamin D supplementation. In these five studies, statistical models predicted a reduction of 50\% to $70 \%$ of relapses, depending on the study, for an increase of $20 \mathrm{ng} / \mathrm{mg}$ in the 25-OH-D serum level (right column). For more details, see text. CIS, clinically isolated syndrome; IMT, immunomodulatory treatment; MS, multiple sclerosis; RR, relapsing-remitting form of MS. 


\subsection{Association studies comparing vitamin D serum levels to other variables in MS patients}

A number of association studies linking vitamin D insufficiency to diverse parameters of the disease have been reported. An exhaustive review of such studies cannot be done here. Some association studies using MRI and testing 25-OH-D serum levels in MS patients have shown that relatively high serum levels were associated with a decrease in the number of new T2 and gadolinium-enhancing lesions (Ascherio et al., 2014; Mowry et al., 2012), thus suggesting a beneficial action of this vitamin in the inflammatory component of the disease. Furthermore, five association or association-intervention studies reported between 2010 and 2016 (Ascherio et al., 2014; Mowry et al., 2010; Laursen et al., 2016b; Pierrot-Deseilligny et al., 2012; Simpson et al., 2010) and analyzing both 25-OH-D serum levels and clinical relapses in MS patients seem to be of particular interest: their main characteristics are given in Table 1. These five studies were methodologically comparable, and their analogous robust statistical models (comprising multivariate analyses) predicted a marked reduction of relapses of 50\%-70\%, according to the study, for each increase of $20 \mathrm{ng} / \mathrm{mL}$ in the 25-OH-D serum level. It may already be considered remarkable that such close figures were observed in five different studies, made on three continents, under diverse climates, in adolescents or adults, with a relapsing-remitting (RR) form of MS or with a CIS, but all at the inflammatory stage of the disease, with or without an associated MS preventive treatment, which could be a first-line or second-line medication, and lastly with or without associated vitamin D supplementation. The fact that so many various contexts led to quasi-similar figures suggests that such quantification may finally represent a good reflection of the specific 'vitamin D effect'. One can be legitimately astonished by the very extent of this effect, which also necessarily has an upper limit. However, if one considers the curves produced by the statistical model in one of the association-intervention studies of this series (Pierrot-Deseilligny et al., 2012), it is first clear that the marked vitamin D effect on relapses was mainly between 26 and $44 \mathrm{ng} / \mathrm{mL}$, i.e. when the initial insufficiency in vitamin D of this cohort was corrected by the supplementation to reach a serum level located within the range generally recommended nowadays (Figure 5). Then, it may be observed that the statistical model generated a clear, unexpected inflexion of the curves resulting in a 'plateau' effect beyond $44 \mathrm{ng} / \mathrm{mg}$, without a further decrease in relapses at higher vitamin $\mathrm{D}$ serum levels. For the moment, such a plateau effect has only been observed in this associationintervention study (Pierrot-Deseilligny et al., 2012) since this is the sole study to have used relatively substantial doses of vitamin $\mathrm{D}(3000 \mathrm{IU} / \mathrm{d})$ resulting in sufficiently high serum levels to reach this plateau and then to confirm it (with serum tests performed every 6 months) throughout a long-lasting follow-up of several years. Furthermore, this study suggests that it is pointless to prescribe very high doses of vitamin D resulting in supra-physiological serum levels (above $60 \mathrm{ng} / \mathrm{mL}$ ), but that it appears nevertheless useful to reach at least the 40-50 $\mathrm{ng} / \mathrm{mL}$ zone of serum levels (and not simply $30 \mathrm{ng} / \mathrm{mL}$ ) to make full use of the vitamin D effect. It should also be noted that most patients of these association-intervention studies likely benefited from this marked effect. Finally, in the durable and maybe definitive absence of major RCTs testing vitamin D supplementation (see above), these different association studies have already given interesting information to decide to supplement MS patients with vitamin D and to choose a supplementation dose at a relatively moderate level (between 2000 and 4000 $\mathrm{IU} / \mathrm{d})$. 


\section{Relapse IRR}

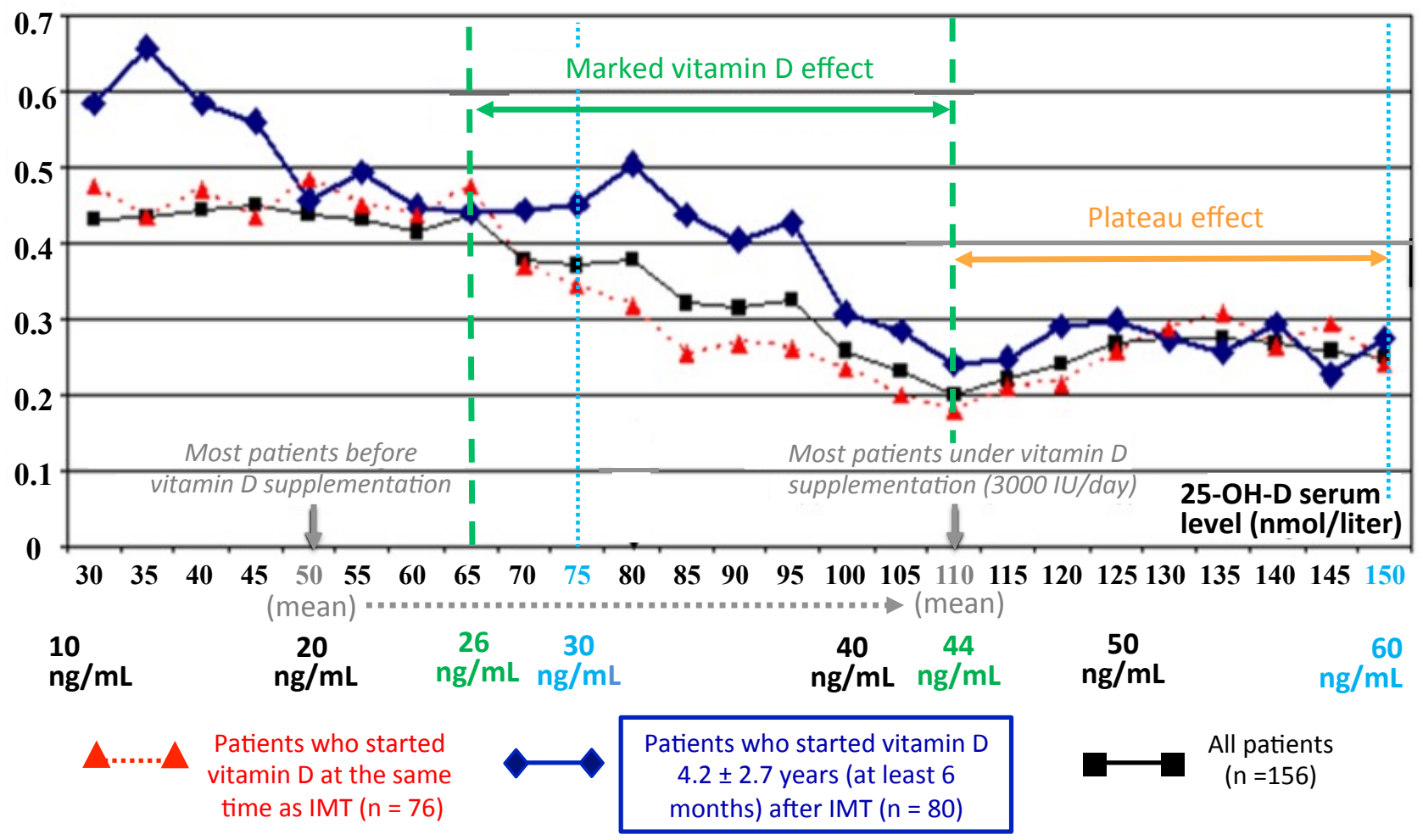

Figure 5. Example of the effect of a continuous moderate supplementation of vitamin D on MS relapses. In this study (Pierrot-Deseilligny et al., 2012), 156 consecutive patients with a relapsing-remitting form of MS (with mean EDSS $=2.01$ ) were given $100000 \mathrm{IU}$ of vitamin D monthly (i.e. with a mean of $3000 \mathrm{IU} / \mathrm{d}$ ) in addition to an injectable first-line IMT and were followed during 2.5 years on average. Their 25-OH-D serum level (tested every 6 months) passed from $20 \mathrm{ng} / \mathrm{mL}$ on average initially, i.e. with a clear vitamin D insufficiency, to $44 \mathrm{ng} / \mathrm{mL}$ on average at the end of the study (gray arrows), i.e. within the limits usually recommended nowadays (in light blue). Using a statistical model of binomial linear regression with multivariate analyses, a highly significant association was found between the vitamin $D$ serum level and the relapse rate $(p<0.0001)$, independent from the IMT action. Furthermore, the model generated the curves shown here and predicted a decrease of 68\% in relapses for an increase of $20 \mathrm{ng} / \mathrm{mL}$ in the vitamin $D$ serum level. The curves show that the marked 'vitamin D effect' was in fact mostly between 26 and 44 $\mathrm{ng} / \mathrm{mL}$, i.e. in a zone corresponding to the correction of vitamin D insufficiency (green arrow). Furthermore, beyond $44 \mathrm{ng} / \mathrm{mL}$, the model produced a clear, unexpected inflexion of the curves resulting in a plateau effect (orange arrow), i.e. without further action on relapses for high serum vitamin D values, which was confirmed throughout the longlasting follow-up. Note that the curve of the patient subgroup that started vitamin D supplementation more than 4 years on average after the IMT (in dark blue), i.e. with an IMT action on relapses that was already effective long before vitamin D addition, was globally analogous to the other curves, which may reflect what could be the specific vitamin D effect. EDSS, expanded disability status scale; IMT, immunomodulatory treatment; IRR, incidence rate ratio; MS, multiple sclerosis. Adapted from Pierrot-Deseilligny et al., 2012.

By contrast, results have been somewhat contradictory for the degenerative, progressive stage of MS, with, in particular, non-significant results in most recent, relatively well-powered studies (Muris et al., 2016b; University of California et al., 2016). Even if an association between vitamin D serum level and disability may at times be found (Hempel et al., 2017), this particular symptom, often resulting in fewer outdoor activities in disabled patients, could contribute to reverse causality (see above), which makes the interpretation of results more difficult. Furthermore, the prevailing impression in observational clinical practice is that vitamin $\mathrm{D}$ is not much more efficient than the other immunomodulatory treatments when the progression of disability is already clinically obvious, i.e. in the secondary or primary progressive forms of the disease. However, it cannot be ruled out that relatively normal vitamin D serum levels existing at an early stage of the disease may decrease the progression of brain atrophy (Mowry et al., 2016) or delay the occurrence of the secondary progressive phase (Murris et al., 2016a), as previously observed with other immunomodulators. 


\subsection{Concluding remarks on clinical studies analyzing the vitamin D effect in MS patients}

In conclusion, from all these studies currently available in MS patients, it appears highly likely that vitamin D markedly decreases the inflammatory component of the disease. Indeed, it can no longer be reasonably argued nowadays that all the positive effects of vitamin D observed on this inflammatory component in the numerous and diverse (clinical, radiological, immunological) reported MS studies, often comprising multivariate analyses, were systematically due to reverse causality and/or to confounding factors, as has at times been suggested (Autier et al., 2014). Even if the inflammation mechanism supposed to 'consume' vitamin D in certain systemic diseases (Ghashut et al., 2014) may be theoretically extended to MS inflammation and then be unlikely incriminated as a factor of reverse causality for all MS association studies (whatever their diverse nature), such a mechanism could not in any case account: 1) for the results of genetic studies specifically linking vitamin D metabolism to MS risk (see above); 2) for the findings of numerous epidemiological studies related to latitude or performed throughout the first part of life, i.e. often a long time before the onset of the disease and prior to any inflammatory stage; 3 ) for the beneficial immunodulatory effects of vitamin D supplementation observed in immunological controlled studies performed in MS patients. Consequently, the main question is no longer to evidence an anti-inflammatory vitamin D effect in MS but rather to calibrate it with greater precision, with however already an approximate answer provided by the association studies reviewed above. Although major RCTs are still required for scientific validation, they are practically more and more difficult to conduct on a topic such as vitamin D and that is why a systematic vitamin D supplementation of MS patients has already been recommended in clinical practice for several years by different specialized teams around the world (Ascherio et al., 2014; Holick, 2012; Holmøy et al., 2012; Jahromi et al., 2016; Jelinek et al., 2015; Pierrot-Deseilligny, 2009; Salzer et al., 2014).

\section{Clinical practice of vitamin D supplementation in MS}

From a pragmatic and practical point of view, while waiting for new scientific information, a vitamin $\mathrm{D}_{3}$ supplementation using moderate oral doses (between 2000 and $4000 \mathrm{IU} / \mathrm{d}$ ) can already be undertaken in all types of MS patients, including pregnant women (Wagner et al., 2017). Such a supplementation dose has several advantages: 1) it corrects the vitamin D insufficiency existing in the great majority of MS patients, with 25-OH-D serum levels thus increasing up to the currently recommended zone (30-60 $\mathrm{ng} / \mathrm{mL}$ ) in most of them (Pierrot-Deseilligny et al., 2012); 2) furthermore, in patients in marked, often deep vitamin D insufficiency, a supplementation should be considered obligatory from a general medical point of view, to prevent osteoporosis, attenuate infections, etc. (Pierrot-Deseilligny and Souberbielle, 2013); 3) a moderate supplementation dose is harmless, in particular without the risk of hypercalcemia or any other serious significant side effect (Hathcock et al., 2007; Pierrot-Deseilligny et al., 2012); 4) this supplementation might also have beneficial effects on the inflammatory component of the disease. In temperate countries, the supplementation should never be stopped since there is no durable storage of this vitamin in the organism. A blood test is useful before supplementation to check the initial calcemia and 25-OH-D serum level, which may be extremely low (below $10 \mathrm{ng} / \mathrm{mL}$ ) as early as the beginning of the disease, but this is often in particular contexts: people systematically avoiding sunshine and/or with dark skin (absorbing less UVB) and/or with skin-covering clothes and/or with obesity. In these cases, a loading dose may be useful at the beginning of supplementation to reach more rapidly an optimal vitamin D status. A control test, around six months after the beginning of supplementation, should be used to check that the patient has been compliant, the optimal 25-OH-D serum zone $(40-60 \mathrm{ng} / \mathrm{mL})$ has been reached and there is no hypercalcemia. Then, even if the first control has been satisfactory, tests should be repeated yearly to check that compliance has been maintained. Lastly, it also appears useful to encourage the avoidance of other risk factors, by recommending that cigarette smokers stop smoking and obese patients lose weight, since risk factors for MS are generally also worsening factors after the start of the disease. These various recommendations may be extended to MS patients' relatives (Sundström and Salzer, 2015) since they have a genetically increased risk for the disease.

\section{Conflicts of interest: none}

No funding source for this article: this research did not receive any specific grant from funding agencies in the public, commercial, or not-for-profit sectors. 
Allen, A., Kelly, S., Basdeo, S., Kinsella, K., Muready, K., Mills, K., et al., 2012. A pilot study of immunological effects of high-dose vitamin D in healthy volunteers. Mult. Scler. 18, 1797-800.

Ascherio, A., Munger, K.L., 2016. Epidemiology of multiple sclerosis: from risk factors to prevention-An update. Semin. Neurol. 36,103-114.

Ascherio, A., Munger, K.L., Lünemann, J.D., 2012. The initiation and prevention of multiple sclerosis. Nat. Rev. Neurol. 8 , $602-612$.

Ascherio, A., Munger, K.L., White, R., Köchert, K., Simon, K.C., Polman, C.H., et al., 2014. Vitamin D as an early predictor of multiple sclerosis activity and progression. JAMA Neurol. 7, 306-14.

Ashtari, F., Toghianifar, N., Zarkesh-Esfahani, S.H., Mansourian, M., 2015. Short-term effect of high-dose vitamin D on the level of interleukin 10 in patients with multiple sclerosis: a randomized, double-blind, placebo-controlled clinical trial. Neuroimmunomodulation 22, 400-404.

Autier, P., Boniol, M., Pizot, C., Mullie, P., 2014. Vitamin D status and ill health: a systematic review. Lancet Diabetes Endocrinol. 2, 76-89.

Azizi, E., Pavlotski, F., Kudish, A., Flint, P., Solomon, A., Lerman, Y., et al., 2012. Serum levels of 25-hydroxy-vitamin D3 among sun-protected outdoor workers in Israel. Photochem. Photobiol. 8, 1507-1512.

Bäärnhielm, M., Hedström, A., Kockum, I., Sundqvist, E., Gustafsson, S., Hillert, J., et al., 2012. Sunlight is associated with decreased MS risk: no interaction with HLA-DRB1*15. Eur. J. Neurol. 19, 955-962.

Bäärnhielm, M., Olsson, T., Alfredsson, L., 2014. Fatty fish intake is associated with decreased occurrence of multiple sclerosis. Mult. Scler. 20, 726-732.

Balbuena, L.D., Middleton, R.M., Tuite-Dalton, K., Pouliou, T., Williams, K.E., Noble, G.J., 2016. Sunshine, sea, and season of birth: MS incidence in Wales. PLoS One 11, e0155181.

Barger-Lux, M.J., Heaney, R.P., 2002. Effects of above average summer sun exposure on serum 25-hydroxyvitamin D and calcium absorption. J. Clin. Endocrinol. Metab. 87, 4952-4956.

Behrens, J.R., Rasche, L., Gieß, R.M., Pfuhl, C., Wakonig, K., Freitag, E., et al., 2016. Low 25-hydroxyvitamin D, but not the bioavailable fraction of 25-hydroxyvitamin D, is a risk factor for multiple sclerosis. Eur. J. Neurol. 23, 62-67.

Beretich, B.D., Beretich, T.M., 2009. Explaining multiple sclerosis prevalence by ultraviolet exposure: a geospatial analysis. Mult. Scler. 15, 891-898.

Bhargava, P., Steele, S.U., Waubant, E., Revirajan, N.R., Marcus, J., Dembele, M., et al., 2016. Multiple sclerosis patients have a diminished serologic response to vitamin D supplementation compared to healthy controls. Mult. Scler. 22, $753-$ 760.

Binkley, N., Krueger, D., 2008. Evaluation and correction of low vitamin D status. Curr. Osteoporos. Rep. 6, 95-99.

Bischoff-Ferrari, H., Willett, W., Orav, E., Lips, P., Meunie, P., Lyons, R., et al., 2012. A pooled analysis of vitamin D requirements for fracture prevention. New Engl. J. Med. 367, 40-49.

Bjørnevik, K., Chitnis, T., Ascherio, A., Munger, K.L., 2017. Polyunsaturated fatty acids and the risk of multiple sclerosis. Mult. Scler. Jan 1:1352458517691150. doi: 10.1177/1352458517691150. [Epub ahead of print]

Bjørnevik, K., Riise, T., Casetta, I., Drulovic, J., Granieri, E., Holmøy, T., et al., 2014. Sun exposure and multiple sclerosis risk in Norway and Italy: The EnvIMS study. Mult. Scler. 20, 1042-1049.

Bove, R., Musallam, A., Healy, B.C., Raghavan, K., Glanz, B.I, Bakshi, R., et al., 2014. Low testosterone is associated with disability in men with multiple sclerosis. Mult. Scler. 20, 1584-1592.

Breuer, J., Schwab N., Schneider-Hohendorf T., Marziniak M., Mohan H., Bhatia, U., et al., 2014. Ultraviolet B light attenuates the systemic immune response in central nervous system autoimmunity. Ann. Neurol. 75, $739-758$.

Budhram, A., Parvathy, S., Kremenchutzky, M., Silverman, M., 2016. Breaking down the gut microbiome composition in multiple sclerosis. Mult. Scler. Dec 12. pii: 1352458516682105. doi: 10.1177/1352458516682105. [Epub ahead of print]

Cantorna, M.T., Snyder, L., Lin, Y.D., Yang, L., 2015. Vitamin D and 1,25(OH)2D regulation of T cells. Nutrients 7, 30113021.

Chidrawar, S., Khan, N., Wei, W., McLarnon, A., Smith, N., Nayak, L., Moss, P., 2009. Cytomegalovirus-seropositivity has a profound influence on the magnitude of major lymphoid subsets within healthy individuals. Clin. Exp. Immunol. 155, 423432. 
Clark, A., Mach, N., 2016. Role of vitamin D in the hygiene hypothesis: the interplay between vitamin D, vitamin D receptors, gut microbiota, and immune response. Front. Immunol. 7, 627.

Correale, J., Gaitán, M.I., 2015. Multiple sclerosis and environmental factors: the role of vitamin D, parasites, and EpsteinBarr virus infection. Acta Neurol. Scand. Suppl. 132, 46-55.

Correale, J., Ysrraelit, M., Gaitán, M., 2009. Immunomodulatory aspects of vitamin D in multiple sclerosis. Brain 132, 1146-1160.

Cortese, M., Riise, T., Bjørnevik, K., Holmøy, T., Kampman, M.T., Magalhaes, S., et al., 2015. Timing of use of cod liver oil, a vitamin D source, and multiple sclerosis risk: The EnvIMS study. Mult. Scler. 21, 1856-1864.

Da Costa, D.S., Hygino, J., Ferreira, T.B., Kasahara, T.M., Barros, P.O., Monteiro, C., et al., 2016. Vitamin D modulates different IL-17-secreting T cell subsets in multiple sclerosis patients. J. Neuroimmunol. 299, 8-18.

Danner, O.K., Matthews, L.R., Francis, S., Rao, V.N., Harvey, C.P., Tobin, R.P., et al., 2016. Vitamin D3 suppresses class II invariant chain peptide expression on activated B-lymphocytes: A plausible mechanism for downregulation of acute inflammatory conditions. J. Nutr. Metab. 2016, 4280876 doi: 10.1155/2016/4280876.

De la Fuente, A.G., Errea, O., van Wijngaarden, P., Gonzalez, G.A., Kerninon, C., Jarjour, A.A., et al., 2015. Vitamin D receptor-retinoid $\mathrm{X}$ receptor heterodimer signaling regulates oligodendrocyte progenitor cell differentiation. J. Cell. Biol. 211, 975-985.

DeLuca, H.F., Plum, L., 2017. UVB radiation, vitamin D and multiple sclerosis. Photochem. Photobiol. Sci. 16, 411-415.

Dobson, R., Giovannoni, G., Ramagopalan, S., 2013. The month of birth effect in multiple sclerosis: systematic review, meta-analysis and effect of latitude. J. Neurol. Neurosurg. Psychiatry 84, 427-432.

Earthman, C., Beckman, L., Masodkar, K., Sibley, S., 2012. The link between obesity and low circulating 25hydroxyvitamin D concentrations: considerations and implications. Int. J. Obes. 3, 387-396.

Fawaz, L., Mrad, M.F., Kazan, J.M., Sayegh, S., Akika, R., Khoury, S.J., 2016. Comparative effect of 25(OH)D3 and 1,25(OH)2D3 on Th17 cell differentiation. Clin. Immunol. 166-167, 59-71.

Fiddes, B., Wason, J., Sawcer, S., 2014. Confounding in association studies: month of birth and multiple sclerosis J. Neurol. 261, 1851-1856.

Ghashut, R.A., Talwar, D., Kinsella, J., Duncan, A., McMillan, D.C., 2014. The effect of the systemic inflammatory response on plasma vitamin $25(\mathrm{OH}) \mathrm{D}$ concentrations adjusted for albumin. PLoS One 9, e92614.

Gianfrancesco, M.A., Strid, P., Rhead, B., Shao, X., Xu, E., Graves, J., et al., 2017. Evidence for a causal relationship between low vitamin D, high BMI and pediatric-onset MS. Neurology, in press.

Gorman, S., Kuritzky, L.A., Judge, M.A., Dixon, K.M., McGlade, J.P., Mason R.S., et al., 2007. Topically applied 1,25dihydroxyvitamin D3 enhances the suppressive activity of CD4+CD25+ cells in the draining lymph nodes. J. Immunol. 179, $6273-6283$.

Grau-Lopez, L., Granada, M., Raich, D., Naranjo, M., Borras, F., Martinez-Caceres, E., et al., 2012. Regulatory role of vitamin $\mathrm{D}$ in T-cell reactivity against myelin peptides in relapsing-remitting multiple sclerosis patients. BMC Neurol. 12:103.

Graves, J.S., Barcellos, L.F., Shao, X., Noble, J., Mowry, E.M., Quach, H., et al., 2016. Genetic predictors of relapse rate in pediatric MS. Mult. Scler. 22, 1528-1535.

Gustavsen, M.W., Page, C.M., Moen, S.M., Bjølgerud, A., Berg-Hansen, P., Nygaard, G.O., et al., 2014 Environmental exposures and the risk of multiple sclerosis investigated in a Norwegian case-control study. BMC Neurol. 14,196.

Haas, J., Schwarz, A., Korporal-Kuhnke, M., Faller, S., Jarius, S., Wildemann, B., 2016. Hypovitaminosis D upscales B-cell immunoreactivity in multiple sclerosis. J. Neuroimmunol. 294, 18-26.

Hall, L., Kimlin, M., Aronov, P., Hammock, B., Slusser, J., Woodhouse, L., 2010. Vitamin D intake needed to maintain target serum 25-hydroxyvitamin D concentrations in participants with low sun exposure and dark skin pigmentation is substantially higher than current recommendations. J. Nutr. 140, 542-550.

Handel, A., Giovannoni, G., Ebers, G., Ramagopalan, S., 2010. Environmental factors and their timing in adult-onset multiple sclerosis. Nat. Rev. Neurol. 6, 156-166.

Handunnetthi, L., Ramagopalan, SV, Ebers, GC, 2010. Multiple sclerosis, vitamin D, and HLA-DRB1*15. Neurology 74, 1905-1910.

Hart, P.H., Gorman, S., 2013. Exposure to UV wavelengths in sunlight suppresses immunity. To what extent is UV-induced vitamin D3 the mediator responsible? Clin. Biochem. Rev. 34, 3-13. 
Hathcock, J., Shao, A., Vieth, R., Heaney, R., 2007. Risk assessment for vitamin D. Am. J. Clin. Nutr. 85, 6-18.

Hayes, C.E., Hubler, S.L., Moore, J.R., Barta, L.E., Praska, C.E., Nashold, F.E., 2015. Vitamin D actions on CD4(+) T cells in autoimmune disease. Front. Immunol. 6, 100.

Hempel, S., Graham, G.D., Fu, N., Estrada, E., Chen, A.Y., Miake-Lye, I., et al., 2017. A systematic review of modifiable risk factors in the progression of multiple sclerosis. Mult. Scler. Feb 1:1352458517690270. doi:

10.1177/1352458517690270. [Epub ahead of print]

Hoel, D.G., Berwick, M., de Gruijl, F.R., Holick, M.F., 2016. The risks and benefits of sun exposure 2016.

Dermatoendocrinol. 8, e1248325.

Holick, M.F., 2011. Vitamin D: evolutionary, physiological and health perspectives. Curr. Drug Targets. $12,4-18$.

Holick, M.F., 2012. Vitamin D: extraskeletal health. Rheum. Dis. Clin. North. Am. 38, 41-60.

Holick, M.F., Binkley, N.C., Bischoff-Ferrari, H.A., Gordon, C.M., Hanley, D.A., Heaney, R.P., et al., 2011. Evaluation, treatment, and prevention of vitamin D deficiency: an Endocrine Society clinical practice guideline. J. Clin. Endocrinol. Metab. 96, 1911-1930.

Holmøy, T., Kampman, M.T., Smolders, J., 2012. Vitamin D in multiple sclerosis: implications for assessment and treatment. Expert. Rev. Neurother. 12, 1101-1112.

Jahromi, S.R., Sahraian, M.A., Togha, M., Sedighi, B., Shayegannejad, V., Nickseresht, A. et al., 2016. Iranian consensus on use of vitamin D in patients with multiple sclerosis. BMC Neurol. 16, 76.

Jelinek, G.A., Marck, C.H., Weiland, T.J., Pereira, N., van der Meer, D.M., Hadgkiss, E.J., 2015. Latitude, sun exposure and vitamin D supplementation: associations with quality of life and disease outcomes in a large international cohort of people with multiple sclerosis. BMC Neurol. 15, 132.

Karaky, M., Alcina, A., Fedetz, M., Barrionuevo, C., Potenciano, V., Delgado, C., et al., 2016. The multiple sclerosisassociated regulatory variant rs 10877013 affects expression of CYP27B1 and VDR under inflammatory or vitamin D stimuli. Mult. Scler. 22, 999-1006.

Koch, M., Metz, L., Kovalchuk O., 2012. Epigenetic changes in patients with multiple sclerosis. Nat. Rev. Neurol. 9, 35-43.

Kragt, J., van Amerongen, B., Killestein, J., Dijkstra, C., Uitdehaag, B., Polman, C., et al., 2009. Higher levels of 25hydroxyvitamin $D$ are associated with a lower incidence of multiple sclerosis only in women. Mult. Scler. 15, 9-15.

Kuhle, J., Disanto, G., Dobson, R., Adiutori, R., Bianchi, L., Topping, J., et al., 2015. Conversion from clinically isolated syndrome to multiple sclerosis: A large multicentre study. Mult. Scler. 21, 1013-1024.

Laursen, J.H., Søndergaard, H.B., Albrechtsen, A., Frikke-Schmidt R., Koch-Henriksen N., Soelberg Sørensen P., et al., 2015. Genetic and environmental determinants of 25-hydroxyvitamin D levels in multiple sclerosis. Mult. Scler. 21, 14141422.

Laursen, J.H., Søndergaard, H.B., Sørensen, P.S., Sellebjerg, F., Oturai, A.B., 2016a Association between age at onset of multiple sclerosis and vitamin D level-related factors. Neurology 86, 88-93.

Laursen, J.H., Søndergaard, H.B., Sørensen, P.S. Sellebjerg, F., Oturai, A.B., 2016b. Vitamin D supplementation reduces relapse rate in relapsing-remitting multiple sclerosis patients treated with natalizumab. Mult. Scler. Relat. Disord.10, 169173.

Lehmann, B. 2009. Role of the vitamin $D_{3}$ pathway in healthy and diseased skin--facts, contradictions and hypotheses. Exp Dermatol. 18, 97-108.

Looker, A.C., Pfeiffer, C.M., Lacher, D.A., Schleicher, R.L., Picciano, M.F., Yetley, E.A., 2008. Serum 25-hydroxyvitamin D status of the US population: 1988-1994 compared with 2000-2004. Am. J. Clin. Nutr. 88, 1519-1527.

Lucas, R.M., Byrne, S.N., Correale J., Ilschner, S., Hart, P.H., 2015. Ultraviolet radiation, vitamin D and multiple sclerosis. Neurodegener. Dis. Manag. 5, 413-424.

Lucas, R., Ponsonby, A., Dear, K., Valery, P., Pender, M., Taylor, B. et al., 2011. Sun exposure and vitamin D are independent risk factors for CNS demyelination. Neurology 76, 540-548.

Luxwolda, M., Kuiperst, R., Kema, I., Dijck- Brouwer, J., Muskiet, F., 2012. Traditionally living populations in East Africa have a mean serum 25-hydroxyvitamin D concentration of $115 \mathrm{nmol} / \mathrm{L}$. Br. J. Nutr. 108, 1557-1561.

Lysandropoulos, A., Jaquiéry, E., Jilek, S., Pantealo, G., Schluep, M., Du Pasquier R., 2011. Vitamin D has a direct immunomodulatory effect on CD8+ T cells of patients with early multiple sclerosis and in healthy controls. J.

Neuroimmunol. 233, 240-244. 
Makhani, N., Banwell, B., Tellier, R., Yea, C., McGovern, S., O'Mahony, J., et al., 2016. Viral exposures and MS outcome in a prospective cohort of children with acquired demyelination. Mult. Scler. 22, 385-388.

Martinelli, V., Dalla Costa, G., Colombo, B., Dalla Libera, D., Rubinacci, A., Filippi, M. et al., 2014. Vitamin D levels and risk of multiple sclerosis in patients with clinically isolated syndromes. Mult. Scler. 20, 147-155.

McCully, M.L., Collins, P.J., Hughes, T.R., Thomas, C.P., Billen, J., O’Donnell, V.B., Moser, B. 2015. Skin metabolites define a new paradigm in the localization of skin tropic memory T cells. J. Immunol. 195, 96-104.

McLeod, J., Hammond, S., Kurtzke, J., 2011. Migration and multiple sclerosis in immigrants to Australia from United Kingdom and Ireland: a reassessment. I. Risk of MS by age at immigration. J. Neurol. 258, 1140-1149.

Mielcarz, D.W., Kasper, L.H., 2015. The gut microbiome in multiple sclerosis. Curr. Treat. Options Neurol. $17,344$.

Mirzaei, F., Michels, K.B., Munger, K., O'Reilly, E., Chitnis, T., Forman, M.R., et al., 2011. Gestational vitamin D and the risk of multiple sclerosis in offspring. Ann. Neurol. 70, 30-40.

Mokry, L.E., Ross, S., Ahmad, O.S., Forgetta, V., Smith, G.D., Leong, A., et al., 2015. Vitamin D and risk of multiple sclerosis: A mendelian randomization study. PLoS Med. 12, e1001866

Mokry, L.E., Ross, S.,Timpson, N.J., Sawcer, S., Smith, G.D., Richards, J.B., 2016. Obesity and multiple sclerosis: a Mendelian randomization study. PLoS Med. 13, e1002053.

Mosayebi, G., Ghazavi, A., Ghasami, K., Kokhaei, P., 2011. Therapeutic effect of vitamin D3 in multiple sclerosis patients. Immunol. Invest. 40, 627-639.

Mowry, E.M., James, J.A., Krupp, L.B., Waubant, E., 2011. Vitamin D status and antibody levels to common viruses in pediatric-onset multiple sclerosis Mult. Scler. 17, 666-671

Mowry, E.M., Krupp, L.B., Milazzi, M., Chabas, D., Strober, J.B., Belman, A.L., et al., 2010. Vitamin D status is associated with relapse rate in pediatric-onset MS. Ann. Neurol. 67, 618-624.

Mowry, E.M., Pelletier, D., Gao, Z., Howell, M.D., Zamvil, S.S., Waubant, E., 2016. Vitamin D in clinically isolated syndrome: evidence for possible neuroprotection. Eur J. Neurol. 23, 327-332.

Mowry, E.M., Waubant, E., McCulloch, C.E., Okuda, D.T., Evangelista, A.A., Lincoln, R.R., et al., 2012. Vitamin D status predicts new brain magnetic resonance imaging activity in multiple sclerosis. Ann. Neurol. 72, 234-240.

Munger, K.L., Åivo, J., Hongell, K., Soilu-Hänninen, M., Surcel, H.M., Ascherio, A., 2016. Vitamin D status during pregnancy and risk of multiple sclerosis in offspring of women in the Finnish maternity cohort. JAMA Neurol. 73, 51-59.

Munger, K.L., Bentzen, J., Laursen, B., Stenager, E., Koch-Henriksen, N., Sorensen, T.I., Baker, J.L., 2013. Childhood body mass index and multiple sclerosis risk: a long-term cohort study. Mult. Scler. 19, 1323-1329.

Munger, K.L., Levin, L.I., Hollis, B.W., Howard, N.S., Ascherio, A., 2006. Serum 25-hydroxyvitamin D levels and risk of multiple sclerosis. JAMA 296, 2832-8.

Munger, K.L., Zhang, S.M., O'Reilly, E., Hernan, M.A., Olek, M.J., Willet, W.C., et al., 2004. Vitamin D intake and incidence of multiple sclerosis. Neurology $62,60-65$.

Muris, A.H., Rolf, L., Broen, K., Hupperts, R., Damoiseaux, J., Smolders, J., 2016a. A low vitamin D status at diagnosis is associated with an early conversion to secondary progressive multiple sclerosis. J. Steroid. Biochem. Mol. Biol. 164, 254257.

Muris, A.H., Smolders, J., Rolf, L., Klinkenberg, L.J., van der Linden, N., Meex, S. et al., 2016b. Vitamin D status does not affect disability progression of patients with multiple sclerosis over three year follow-Up. PLoS One 11, e0156122.

Muris, A.H., Smolders, J., Rolf, L., Thewissen, M., Hupperts, R., Damoiseaux, J., SOLARIUM study group, 2016c. Immune regulatory effects of high dose vitamin $\mathrm{D} 3$ supplementation in a randomized controlled trial in relapsing remitting multiple sclerosis patients receiving IFN $\beta$; the SOLARIUM study. J. Neuroimmunol. 300, 47-56.

Nadkarni, S, McArthur, S., 2013. Oestrogen and immunomodulation: new mechanisms that impact on peripheral and central immunity. Curr. Opin. Pharmacol. 13, 576-581.

Nair, R.R., Verma, P., Singh, K., 2017. Immune-endocrine crosstalk during pregnancy. Gen. Comp. Endocrinol. 242, 1823.

Nielsen, N.M., Munger, K.L., Koch-Henriksen, N., Hougaard D.M., Magyari, M., Jørgensen, K.T., et al., 2017. Neonatal vitamin D status and risk of multiple sclerosis: A population-based case-control study. Neurology $88,44-51$.

Norman, A., Bouillon, R., 2010. Vitamin D nutritional policy needs a vision for the future. Exp. Biol. Med. 235, 1034-1045. 
Olsson, T., Barcellos, L.F., Alfredsson, L., 2017. Interactions between genetic, lifestyle and environmental risk factors for multiple sclerosis. Nat. Rev. Neurol. 13, 25-36.

O’Neill, C.M., Kazantzidis, A., Ryan, M.J., Barber, N., Sempos, C.T., Durazo-Arvizu, R.A. et al., 2016. Seasonal changes in vitamin D-effective UVB availability in Europe and associations with population serum 25-Hydroxyvitamin D. Nutrients 8 , 533.

Patas, K., Engler, J.B., Friese, M.A., Gold, S.M., 2013. Pregnancy and multiple sclerosis: feto-maternal immune cross talk and its implications for disease activity. J. Reprod. Immunol. 97, 140-146.

Pierrot-Deseilligny, C., 2009. Clinical implications of a possible role of vitamin D in multiple sclerosis. J. Neurol. 256, 14681479.

Pierrot-Deseilligny, C., Rivaud-Péchoux, S., Clerson, P., de Paz, R., Souberbielle J.C., 2012. Relationship between 25$\mathrm{OH}-\mathrm{D}$ serum level and relapse rate in multiple sclerosis patients before and after vitamin $\mathrm{D}$ supplementation. Ther. Adv. Neurol. Disord. 5, 187-198.

Pierrot-Deseilligny, C., Souberbielle, J.C., 2010. Is hypovitaminosis D one of the environmental risk factors for multiple sclerosis? Brain 133, 1869-1888.

Pierrot-Deseilligny, C., Souberbielle, J.C., 2013. Contribution of vitamin D insufficiency to the pathogenesis of multiple sclerosis. Ther. Adv. Neurol. Disord. 6, 81-116.

Pike, J.W., Meyer, M.B., 2012. The vitamin D receptor: new paradigms for the regulation of gene expression by $1,25-$ dihydroxyvitamin D3. Rheum. Dis. Clin. North Am. 38, 13-27.

Płudowski, P., Karczmarewicz, E., Bayer, M., Carter, G., Chlebna-Sokół, D., Czech-Kowalska, J., et al., 2013. Practical guidelines for the supplementation of vitamin $D$ and the treatment of deficits in Central Europe - recommended vitamin $D$ intakes in the general population and groups at risk of vitamin D deficiency. Endokrynol. Pol. 64, 319-327.

Ramagopalan, S.V., Handel, A.E., Giovannoni, G., Rutherford Siegel, S, Ebers, G.C., 2011. Chaplin, G. Relationship of UV exposure to prevalence of multiple sclerosis in England. Neurology 76, 1410-1414.

Ramagopalan, S.V., Maugeri, N.J., Handunnetthi, I., Lincoln, M.R., Orton, S.M., Dyment, D.A. et al., 2009. Expression of the multiple sclerosis-associated MHC class II Allele HLA-DRB1*1501 is regulated by vitamin D. PLoS Genet. 5, e1000369.

Ramasamy, A., Trabzuni, D., Forabosco, P., Smith, C., Walker, R., Dillman, A., et al., 2014. Genetic evidence for a pathogenic role for the vitamin D3 metabolizing enzyme CYP24A1 in multiple sclerosis. Mult. Scler. Relat. Disord. 3, 211219.

Ramien, C., Pachnio, A., Sisay, S., Begum, J., Leese, A., Disanto, G., et al., 2014. Hypovitaminosis-D and EBV: no interdependence between two MS risk factors in a healthy young UK autumn cohort. Mult. Scler. 20, 751-753.

Rhead, B., Bäärnhielm, M., Gianfrancesco, M., Mok, A., Shao, X., Quach, H., et al., 2016. Mendelian randomization shows a causal effect of low vitamin D on multiple sclerosis risk. Neurol. Genet. 2, e97.

Ricigliano, V.A., Handel, A.E., Sandve, G.K., Annibali, V., Ristori, G., Mechelli, R., et al., 2015. EBNA2 binds to genomic intervals associated with multiple sclerosis and overlaps with vitamin D receptor occupancy. PLoS One 10, e0119605.

Rodríguez Cruz, P.M., Matthews, L., Boggild, M., Cavey, A., Constantinescu, C.S., Evangelou, N., et al., 2016. Time- and region-specific season of birth effects in multiple sclerosis in the United Kingdom. JAMA Neurol. 73, 954-960.

Rolf, L., Muris, A.H., Hupperts, R., Damoiseaux, J., 2014. Vitamin D effects on B cell function in autoimmunity. Ann. N. Y. Acad. Sci. 1317, 84-91.

Røsjø, E., Lossius, A., Abdelmagid, N., Lindstrøm, J.C., Kampman, M.T., Jørgensen, L., et al., 2017. Effect of high-dose vitamin D3 supplementation on antibody responses against Epstein-Barr virus in relapsing-remitting multiple sclerosis. Mult. Scler. 23,395-402.

Ross, A., Manson, E., Abrams, S., Aloia, J., Brannon, P., Steven, K., et al., 2011. The 2011 report on dietary reference intakes for calcium and vitamin D from the Institute of Medicine: what clinicians need to know. J. Clin. Endocrinol. Metab. 96, 53-58.

Salzer, J., Biström, M., Sundström, P., 2014. Vitamin D and multiple sclerosis: where do we go from here? Expert. Rev. Neurother. 14, 9-18.

Salzer, J., Hallmans, G., Nyström, M., Stenlund, H., Waell, G., Sundström P., 2012. Vitamin D as a protective factor in multiple sclerosis. Neurology 79, 2140-2145.

Salzer, J., Nyström, M., Hallmans, G., Stenlund, H., Wadell, G., Sundström, P., 2013. Epstein-Barr virus antibodies and vitamin $D$ in prospective multiple sclerosis biobank samples. Mult. Scler. 19, 1587-1591. 
Sandberg, L., Biström, M., Salzer, J., Vågberg, M., Svenningsson, A., Sundström, P., 2016. Vitamin D and axonal injury in multiple sclerosis. Mult. Scler. 22, 1027-1031.

Sawcer, S.A., Hellenthai, G., Pirinen, M., Spencer, C.C.A., Patsopoulos, N.A., Moutsanias, L., et al., 2011. The International Multiple Sclerosis Genetics Consortium and Wellcome Trust Case Control Consortium 2 Genetic risk and primary role for cell-mediated immune mechanisms in multiple sclerosis. Nature 476, 214-219.

Schuessler, M., Astecker, N., Herzig, G., Vorisek, G., Schuster, I., 2001. Skin is an autonomous organ in synthesis, two-step activation and degradation of vitamin D(3): CYP27 in epidermis completes the set of essential vitamin D(3)-hydroxylases. Steroids 66, 399-408.

Shirazi, H.A., Rasouli, J., Ciric, B., Rostami, A., Zhang, G.X., 2015. 1,25-Dihydroxyvitamin $D_{3}$ enhances neural stem cell proliferation and oligodendrocyte differentiation. Exp. Mol. Pathol. 98, 240-245.

Simon, K.C., Munger, K.L., Kraft, P., Hunter, D.J., De Jager, P.L., Ascherio, A., 2011. Genetic predictors of 25hydroxyvitamin D levels and risk of multiple sclerosis. J. Neurol. 258, 1676-1682.

Simpson, S. Jr., Blizzard, L., Otahal, P., Van der Mei, I., Taylor, B., 2011. Latitude is significantly associated with the prevalence of multiple sclerosis: a meta-analysis. J. Neurol. Neurosurg. Psychiatry 82, 1132-1141.

Simpson, S., Taylor, B., Blizzard, L., Ponsonby, A.L., Pittas, F., Tremlett, H., et al., 2010. Higher 25-hydroxyvitamin D is associated with lower relapse risk in MS. Ann. Neurol. 68, 193-203.

Sloka, S., Silva, C., Pryse-Phillips, W., Patten, S., Metz, L., Yong, V.W., 2011. A quantitative analysis of suspected environmental causes of MS. Can. J. Neurol. Sci. 38, 98-105.

Smolders, J., Moen, S.M., Damoiseaux, J., Huitinga, I., Holmøy, T., 2011. Vitamin D in the healthy and inflamed central nervous system: access and function. J. Neurol. Sci. 311, 37-43.

Smolders, J., Menheere, P., Thewissen, M., Peelen, E., Tervaert, J., Hupperts, R., et al., 2010. Regulatory T cell function correlates with serum 25-hydroxyvitamin $\mathrm{D}$, but not with 1,25 dihydroxyvitamin $\mathrm{D}$, parathyroid hormone and calcium levels in patients with relapsing remitting multiple sclerosis. J. Steroid Biochem. Mol. Biol. 121, 243-246.

Smolders, J., Thewissen, M., Peelen, E., Menheere, P., Tervaert, J.W., Damoiseaux, J., et al., 2009. Vitamin D status is positively correlated with regulatory $T$ cell function in patients with multiple sclerosis. PLoS One 4, e6635.

Sommer, A., Fabri, M., 2015. Vitamin D regulates cytokine patterns secreted by dendritic cells to promote differentiation of IL-22-producing T cells. PLoS One 10, e0130395.

Sotirchos, E.S., Bhargava, P., Eckstein, C., Van Haren, K., Baynes, M., Ntranos, A., et al., 2016. Safety and immunologic effects of high- vs low-dose cholecalciferol in multiple sclerosis. Neurology $86,382-389$.

Souberbielle, J.C., Body, J.J., Lappe, J.M., Plebani, M., Shoenfeld, Y., Wang, T.J., et al., 2010. Vitamin D and musculoskeletal health, cardiovascular disease, autoimmunity and cancer: recommendations for clinical practice. Autoimmun. Rev. 9, 709-715.

Spanier, J.A., Nashold, F.E., Mayne, C.G., Nelson, C.D., Hayes, C.E., 2015. Vitamin D and estrogen synergy in Vdrexpressing CD4(+) T cells is essential to induce Helios(+)FoxP3(+) T cells and prevent autoimmune demyelinating disease. J. Neuroimmunol. 286, 48-58.

Sundqvist, E., Bäärnhielm, M., Alfredsson, L., Hillert, J., Olsson, T., Kockum, I., 2010. Confirmation of association between multiple sclerosis and CYP27B1. Eur. J. Hum. Genet. 18, 1349-1352.

Sundqvist, E., Bergström, T., Daialhosein, H., Nyström, M., Sundström, P., Hillert, J., et al., 2014. Cytomegalovirus seropositivity is negatively associated with multiple sclerosis. Mult. Scler. 20, 165-173.

Sundström, P., Salzer, J., 2015. Vitamin D and multiple sclerosis-from epidemiology to prevention. Acta Neurol. Scand. Suppl. 132, 56-61.

Tamblyn, J.A., Hewison, M., Wagner, C.L., Bulmer, J.N., Kilby, M.D., 2015. Immunological role of vitamin D at the maternal-fetal interface. J. Endocrinol. 224, R107-121.

Tan, I.J., Peeva, E., Zandman-Goddard, G., 2015. Hormonal modulation of the immune system - A spotlight on the role of progestogens. Autoimmun. Rev.14, 536-542.

Tao, C., Simpson, S. Jr., Taylor, B.V., van der Mei, I., 2017. Association between human herpesvirus \& human endogenous retrovirus and MS onset \& progression. J. Neurol. Sci. 372, 239-249.

Thangamani, S., Kim, M., Son, Y., Huang, X., Kim, H., Lee, J.H., et al., 2015. Cutting edge: progesterone directly upregulates vitamin d receptor gene expression for efficient regulation of T cells by calcitriol. J. Immunol. 194, 883-886. 
Tremlett, H., Fadrosh, D.W., Faruqi, A.A., Hart, J., Roalstad, S., Graves, J., et al., 2016. Associations between the gut microbiota and host immune markers in pediatric multiple sclerosis and controls. BMC Neurol. 16, 182.

Tulic, M.K., Andrews, D., Crook, M.L., Charles, A., Tourigny, M.R., Moqbel, R., Prescott, S.L., 2012. Changes in thymic regulatory T-cell maturation from birth to puberty: differences in atopic children. J. Allergy Clin. Immunol. 129, $199-206$.

University of California, San Francisco MS-EPIC Team, Cree, B.A., Gourraud, P.A., Oksenberg, J.R., Bevan, C., CrabtreeHartman, E., et al., 2016. Long-term evolution of multiple sclerosis disability in the treatment era. Ann. Neurol. 80, 499-510.

Van der Mei, I.A.F., Ponsonby, A.L., Dwyer, T., Blizzard, L., Simmons, R., Taylor, B.V., et al., 2003. Past exposure to sun, skin phenotype, and risk of multiple sclerosis: case-control study. BMJ 327, 1-6.

Vijayendra, Chary A., Hemalatha, R., Seshacharyulu, M., Vasudeva Murali, M., Jayaprakash, D., Dinesh Kumar B., 2015. Reprint of "Vitamin D deficiency in pregnant women impairs regulatory T cell function". J. Steroid. Biochem. Mol. Biol. 148, 194-201.

Von Essen, M., Kongsbak, M., Schjerling, P., Olgaard, K., Odum, N., Geisler, C., 2010. Vitamin D controls T cell antigen receptor signaling and activation of human T cells. Nat. Immunol. 4, 344-349.

Wacker, M., Holick, M.F., 2013. Sunlight and Vitamin D: A global perspective for health. Dermatoendocrinol. 5, 51-108.

Wagner, C.L., Hollis, B.W., Kotsa, K., Fakhoury, H., Karras, S.N., 2017. Vitamin D administration during pregnancy as prevention for pregnancy, neonatal and postnatal complications. Rev. Endocr. Metab. Disord. Feb 18. doi: 10.1007/s11154-017-9414-3. [Epub ahead of print]

Waubant, E., Mowry, E.M., Krupp, L., Chitnis, T., Yeh, E.A., Kuntz, N., et al., 2011. Common viruses associated with lower pediatric multiple sclerosis risk. Neurology 76, 1989-1995.

Waubant, E., Ponsonby, A.L., Pugliatti, M., Hanwell, H., Mowry, E.M., Hintzen, R.Q., 2016. Environmental and genetic factors in pediatric inflammatory demyelinating diseases Neurology. 87(9 Suppl 2), S20-27.

Wergeland, S., Myhr, K.M., Løken-Amsrud, K.I., Beiske, A.G., Bjerve, K.S., Hovdal, H., et al., 2016. Vitamin D, HLA-DRB1 and Epstein-Barr virus antibody levels in a prospective cohort of multiple sclerosis patients. Eur. J. Neurol. 23, 1064-1070.

Wesnes, K., Riise, T., Casetta, I., Drulovic, J., Granieri, E., Holmøy, T., et al., 2015. Body size and the risk of multiple sclerosis in Norway and Italy: The EnvIMS study. Mult. Scler. 21, 388-395.

Yadav, S.K., Mindur, J.E., Ito, K., Dhib-Jalbut, S., 2015. Advances in the immunopathogenesis of multiple sclerosis. Curr. Opin. Neurol. 28, 206-219.

Zhao, D., Ouyang, P., de Boer, I.H., Lutsey, P.L., Farag, Y.M., Guallar, E., et al., 2017. Serum vitamin D and sex hormones levels in men and women: The Multi-Ethnic Study of Atherosclerosis (MESA). Maturitas 96, 95-102.

Zhuang, J.C., Huang, Z.Y., Zhao, G.X., Yu, H., Li, Z.X., Wu, Z.Y., 2015. Variants of CYP27B1 are associated with both multiple sclerosis and neuromyelitis optica patients in Han Chinese population. Gene 557, 236-239. 